Acta Crystallographica Section B

Structural

Science

ISSN 0108-7681

Stephen A. Moggach, ${ }^{a} *$ David R. Allan, ${ }^{\text {a }}$ Stewart J. Clark, Matthias J. Gutmann, ${ }^{c}$ Simon Parsons, ${ }^{a}$ Colin R. Pulham ${ }^{\mathrm{a}}$ and Lindsay Sawyer ${ }^{d}$

${ }^{a}$ School of Chemistry and Centre for Science at Extreme Conditions, The University of Edinburgh, King's Buildings, West Mains Road, Edinburgh EH9 3JJ, Scotland, 'SChool of Physics and Astronomy and Centre for Science at Extreme Conditions, The University of Edinburgh, King's Buildings, West Mains Road, Edinburgh EH9 3JZ, Scotland, ' ISIS Facility, Rutherford Appleton Laboratory, Didcot, Oxfordshire OX11 0QX, England, and Institute for Cell and Molecular Biology and Centre for Science at Extreme Conditions, The University of Edinburgh, King's Buildings, West Mains Road, Edinburgh EH9 3JR, Scotland

Correspondence e-mail: s.moggach@ed.ac.uk

\title{
High-pressure polymorphism in L-cysteine: the crystal structures of L-cysteine-III and L-cysteine-IV
}

The crystal structure of the orthorhombic phase of L-cysteine (hereafter L-cysteine-I) consists of chains of molecules linked via $\mathrm{NH}$... O hydrogen bonds. The chains are linked into a layer by other $\mathrm{NH} \cdots \mathrm{O}$ hydrogen bonds, forming $R_{4}^{4}(16)$ ring motifs. The layers are linked by further NH..O and disordered $\mathrm{SH}$...S/SH...O interactions. The main effects of compression to $1.8 \mathrm{GPa}$ are to contract voids in the middle of the $R_{4}^{4}(16)$ rings and to reduce $\mathrm{S}$...S distances from 3.8457 (10) to 3.450 (4) $\AA$. The latter is at the lower limit for $\mathrm{S}$...S distances and we suggest that strain about the $\mathrm{S}$ atom is responsible for the formation of a new phase of L-cysteine, $\mathrm{L}$ cysteine-III, above $1.8 \mathrm{GPa}$. The phase transition is accompanied by a change in the NCCS torsion angle from $\mathrm{ca} 60$ to $\mathrm{ca}$ $-60^{\circ}$ and small positional displacements, but with no major changes in the orientations of the molecules. The structure of L-cysteine-III contains similar $R$-type ring motifs to L-cysteineI, but there are no S $\cdots S$ contacts within $3.6 \AA$. L-Cysteine-III was found to be stable to at least $4.2 \mathrm{GPa}$. On decompression to $1.7 \mathrm{GPa}$, another single-crystal to single-crystal phase transition formed another previously uncharacterized phase, L-cysteine-IV. This phase is not observed on increasing pressure. The structure consists of two crystallographically independent cysteine molecules in the same conformations as those found in L-cysteine-I and L-cysteine-III. The structure separates into zones with are alternately phase I-like and phase III-like. L-Cysteine-IV can therefore be thought of as an unusual example of an intermediate phase. Further decompression to ambient pressure generates L-cysteine-I.

\section{Introduction}

The response of crystalline molecular solids to high hydrostatic pressure is a rapidly advancing area of interest in smallmolecule crystallography. The extent to which the anisotropy of compressibility can be explained and how far a structure can be compressed before it undergoes a phase transition are key issues of current interest. These areas have has been the subject of a number of recent reviews, for example Boldyreva (2003, 2004a, 2004b), Katrusiak (2004) and Hemley \& Dera (2000).

Within the field of organic crystal chemistry a number of monofunctional alcohols (e.g. Allan et al., 2001; McGregor et al., 2005; Moggach, Allan, Lozano-Casal \& Parsons, 2005), phenols (e.g. Oswald et al., 2005), ketones (Allan et al., 1999), carboxylic acids (e.g. Allan \& Clark, 1999) and amines (Lozano-Casal et al., 2005) have been investigated and shown to be polymorphic at high pressure when crystals are grown by application of pressure to pure liquids. In polyfunctional systems, polymorphs of pharmaceutical compounds have been produced when crystals are grown by careful application of
Received 20 September 2005

\author{
Accepted 22 November 2005
}

(C) 2006 International Union of Crystallography Printed in Great Britain - all rights reserved 
pressure to a concentrated solution (Fabbiani et al., 2003, 2004; Fabbiani, Allan, Parsons \& Pulham, 2005; Fabbiani, Allan, Marshall et al., 2005). We have recently described the effect of compression of the three solid forms of glycine (Dawson et al., 2005). Although $\alpha$-glycine is stable to $23 \mathrm{GPa}$ (Murli et al., 2003), the $\beta$ and $\gamma$ polymorphs respectively transform to the high-pressure $\delta$ and $\varepsilon$ polymorphs on compression of the solids. L-Serine-I transforms to a high-pressure polymorph (Lserine-II) at 4.8 GPa (Moggach, Allan, Morrison, Parsons \& Sawyer, 2005).

While compression of a single-crystal of $\gamma$-glycine yields the $\varepsilon$ phase as a polycrystalline solid, both $\beta$-glycine and L-serine-I both undergo single-crystal to single-crystal phase transitions to high-pressure polymorphs. The transition from one singlecrystalline form to another depends on the similarity of the topology and orientations of the molecules in the two phases.
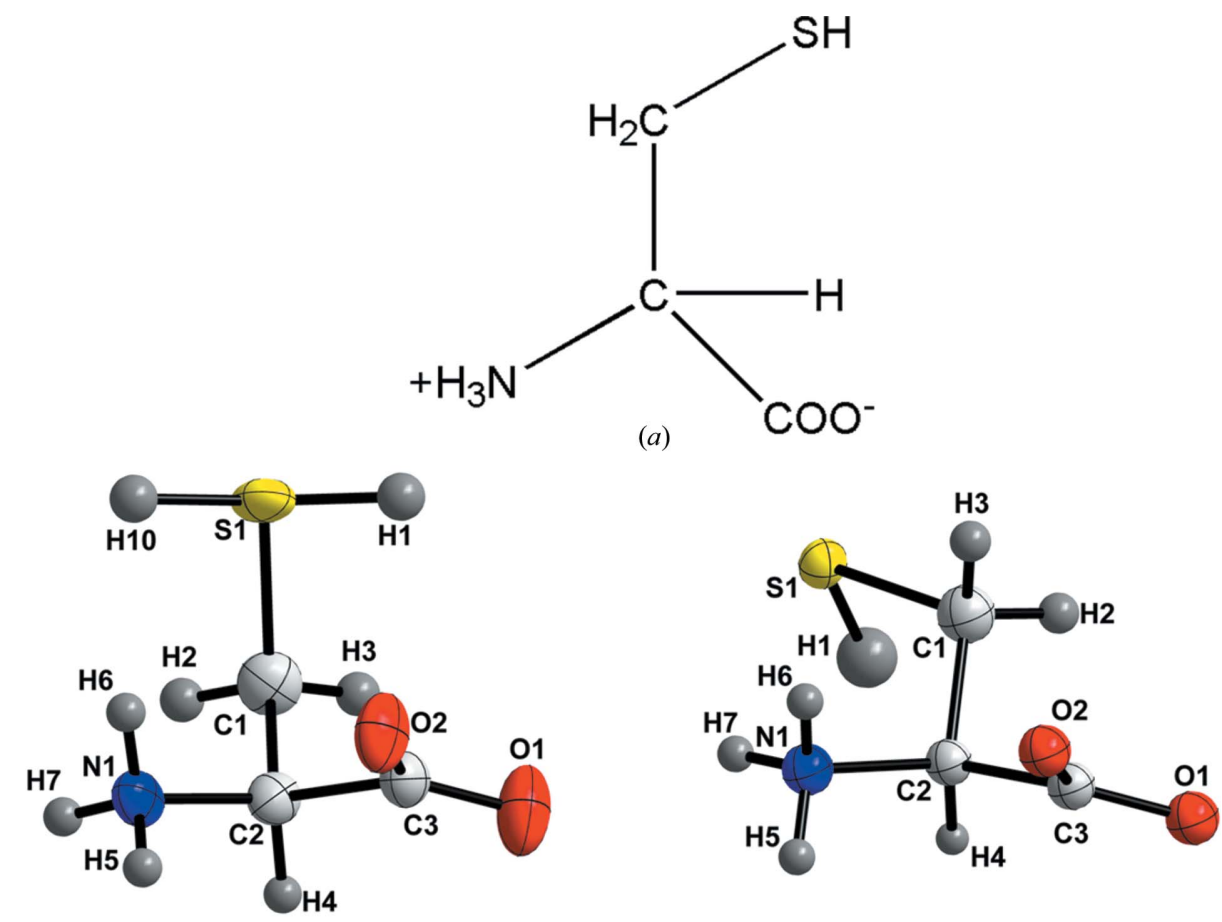

(b)

(c)
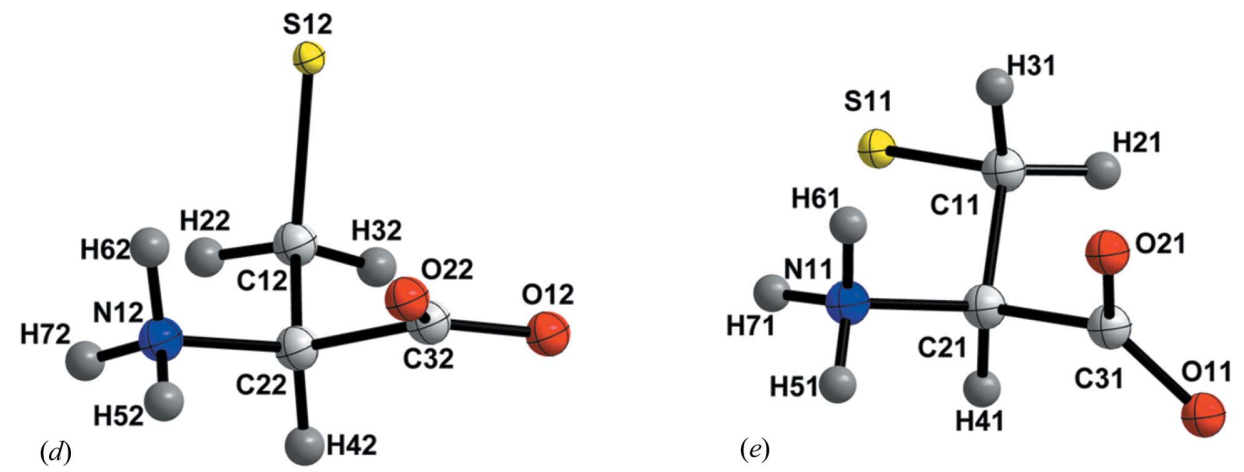

(e)

Figure 1

(a) The chemical structure of L-cysteine in its zwitterionic form. Displacement ellipsoid plots showing numbering schemes for $(b)$ L-cysteine-I (at ambient pressure and ambient temperature), (c) L-cysteine-III and $(d) /(e)$ L-cysteine-IV. All displacement ellipsoids are drawn at $30 \%$ probability. Note $(d)$ and $(e)$ are referred to in the text as molecules 2 and 1 , respectively.
The $\beta$-to- $\delta$-glycine transition is accomplished by a quite modest conformational change of the glycine molecules; the Lserine-I to L-serine-II transition is characterized by a change in the $\mathrm{H}-\mathrm{O}-\mathrm{C}-\mathrm{C}$ torsion angle and a small shift of the molecules relative to each other. In the $\gamma$-to- $\varepsilon$-glycine transition a more substantial reorientation of the molecules occurs, leading to the break-up of the crystal.

The relative compressibility of crystals of serine and glycine, as well as cystine and several other amino acids, along different crystallographic directions could all be rationalized in terms of the distributions and shapes of intermolecular voids. Hydrogen bonds and other intermolecular interactions formed along the directions in which the voids compress shorten substantially, while other such interactions may be left relatively unchanged. $\mathrm{CH}$...O hydrogen bonds also increase in strength and number. It was notable that compression continued until the minimum distance as observed for a specific interaction (e.g. the $\mathrm{N} \cdots \mathrm{O}$ distance in an $\mathrm{N}-\mathrm{H} \cdots \mathrm{O}$ hydrogen bond) under ambient pressure had been reached (i.e. super-short hydrogen bonds are apparently not formed up to $c a$ $10 \mathrm{GPa}$ ) and it was at this point that a phase transition occurred. However, the extent to which these observations have any generality still needs to be established.

Cysteine is an important amino acid in biology. Although the average amount present in proteins is less than $2 \%$, the properties of its side-chain thiol suit it to metal-binding both intraand extra-cellularly. Generally, within the reducing environment of the cell, it exists as cysteine while its oxidation to cystine provides a covalent cross-link in many secreted proteins like insulin and trypsin. At relatively modest pressures $(0.3-0.8 \mathrm{GPa})$ proteins tend to unfold, water being forced into their interior (Hummer et al., 1998) and to date, it is unclear how the effects of pressure are related to the aminoacid composition. As a prelude to answering this question, we are examining the effects of pressure on the individual amino acids and we now describe the effect of pressure (up to $4.3 \mathrm{GPa}$ ) on the crystal structure of the orthorhombic phase of L-cysteine. 
Table 1

Crystallographic data for L-cysteine at ambient temperature and pressure, and at increasing pressures.

Phase of L-cysteine present is indicated by superscripted Roman numerals.

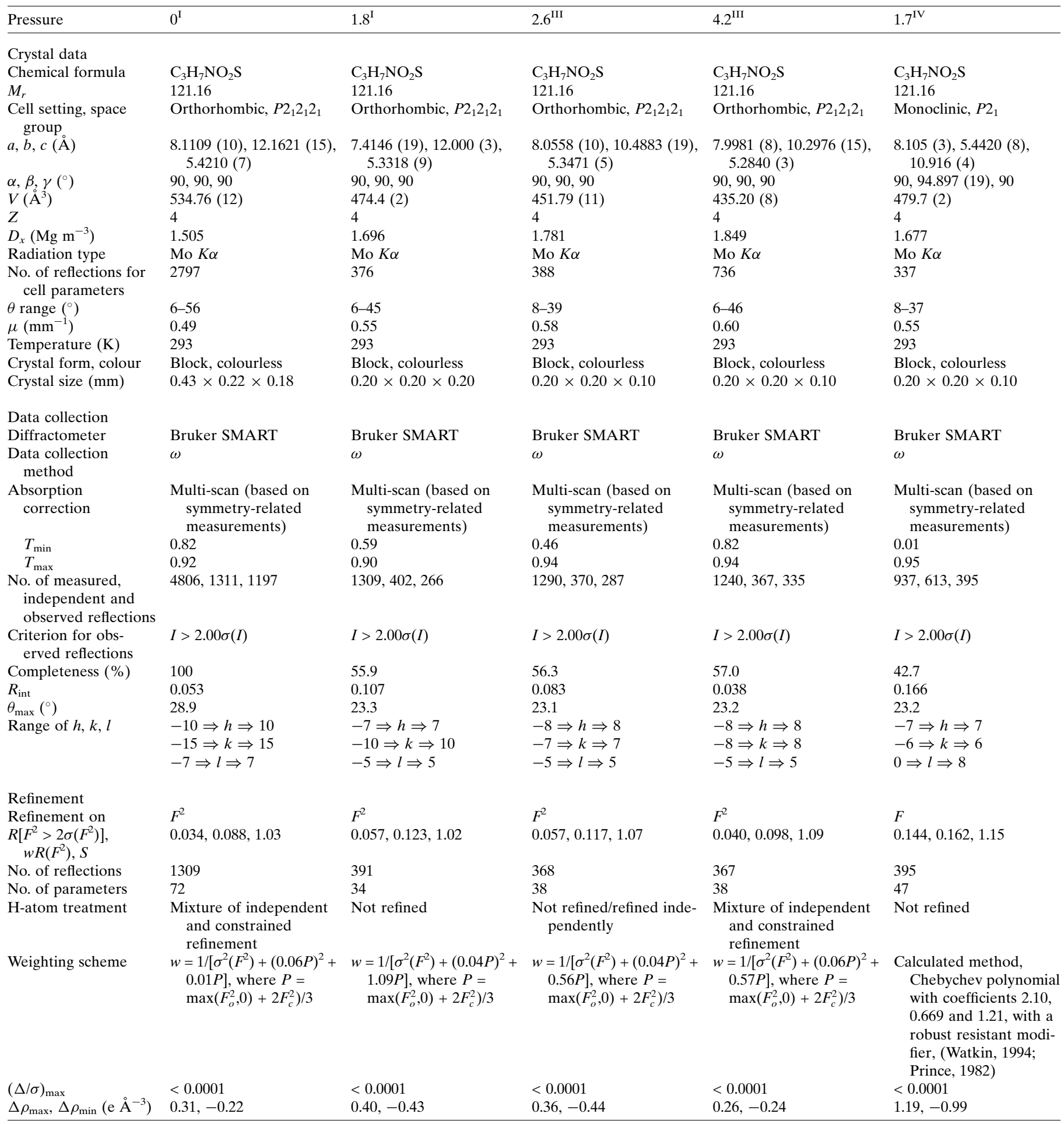

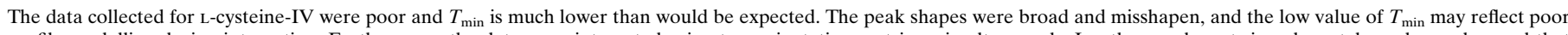

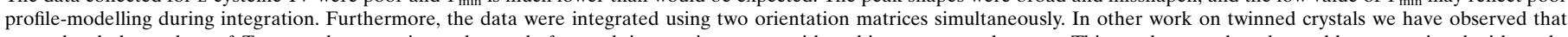

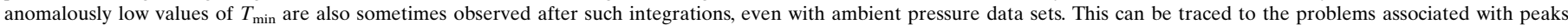
containing partially overlapped contributions from the different twin domains.

Prior to this work, L-cysteine (Fig. $1 a$ ) was known to crystallize in two forms, an orthorhombic phase $\left(P 2_{1} 2_{1} 2_{1}, Z^{\prime}=1\right)$ and a monoclinic phase $\left(P 2{ }_{1}, Z^{\prime}=2\right)$. We refer to these phases as L-cysteine-I and L-cysteine-II, respectively. The crystal structure of the orthorhombic form, L-cysteine-I, was determined by Kerr \& Ashmore (1973) by X-ray diffraction and 
then again by Kerr et al. (1975) by neutron diffraction. We have also recently determined the structure at $30 \mathrm{~K}$ (Moggach, Clark \& Parsons, 2005). L-Cysteine-II was characterized at ambient temperature by Harding \& Long (1968) and later by Görbitz \& Dalhus (1996) at $120 \mathrm{~K}$; both these determinations employed X-ray diffraction. The structure of the racemate, D,L-cysteine, was determined by Luger \& Weber (1999).

\section{Experimental}

\subsection{General procedures}

Crystals of orthorhombic L-cysteine-I obtained from Sigma ( $99 \%$, catalogue number $\mathrm{G}, 1002$ ) were used as received.

High-pressure experiments were carried out using a Merrill-Bassett diamond-anvil cell (half-opening angle $40^{\circ}$ ), equipped with $600 \mu \mathrm{m}$ culets and a tungsten gasket (Merrill \& Bassett, 1974). A small ruby chip was also loaded into the cell as a pressure calibrant, with the ruby-fluorescence method being used to measure the pressure (Piermarini et al., 1975).

\subsection{Diffraction data collection and processing}

In all except one case (see below), diffraction data were collected at room temperature on a Bruker Smart APEX diffractometer (Bruker, 2002) with graphite-monochromated Mo $K \alpha$ radiation $(\lambda=0.71073 \AA)$. High-pressure data collection and processing procedures were as described by Dawson et al. (2004). Integrations were carried out using the program SAINT (Bruker, 2004). Absorption corrections were applied in a two-stage procedure with the programs SHADE (Parsons, 2004) and $S A D A B S$ (Sheldrick, 2004a) for the high-pressure data sets, or with $S A D A B S$ alone for ambient-pressure data.

\subsection{L-Cysteine-I at ambient pressure and temperature}

A sphere of data was collected on a crystal of L-cysteine-I at ambient temperature and pressure in order to provide data for comparison with the high-pressure studies. Refinement was carried out against $|F|^{2}$ using all data (CRYSTALS; Betteridge et al., 2003) starting from the ambient pressure coordinates of Kerr et al. (1975). The thiol $\mathrm{H}$ atom was disordered over two sites and these sites were both located in a slant-plane difference map (Marching Cubes; Hušák \& Kratochvila, 2003); the positions and occupancies were refined subject to the restraint that the $\mathrm{S}-\mathrm{H}$ distances were 1.34 (1) $\AA$; all other $\mathrm{H}$ atoms were placed geometrically. The final conventional $R$ factor was 0.0343 for 1197 data. Listings of crystal and refinement data are given in Table $1 ; ;$ the structure is depicted in Fig. 1(b).

The numbering schemes (Fig. 1) used in all polymorphs of L-cysteine described here are the same as the CSD refcode LCYSTN12 (Kerr et al., 1975). The settings of the structures reported here are also the same as those used in LCYSTN12.

\footnotetext{
${ }^{1}$ Supplementary data for this paper are available from the IUCr electronic archives (Reference: BS5023). Services for accessing these data are described at the back of the journal.
}

\subsection{Compression of L-cysteine-I studied by single-crystal X- ray diffraction}

In order to ensure that the pressure applied to a crystal held in a diamond-anvil cell is uniform, it is necessary to immerse the sample in a medium which displays hydrostatic behaviour throughout the pressure range of interest. Two media used commonly in high-pressure work are a 1:1 mixture of pentane and isopentane and a 4:1 mixture of methanol and ethanol. Compression studies were carried out with both of these media, but slightly different results were obtained.

\subsection{Compression using pentane/isopentane as a hydrostatic medium}

Compression data were collected using a block-shaped crystal of L-cysteine-I, loaded with a 1:1 mixture of pentane and isopentane as the hydrostatic medium. Pressure was increased in approximately $0.9 \mathrm{GPa}$ steps from $0.1 \mathrm{GPa}$ with $\mathrm{X}$-ray diffraction data being collected at each stage. Above $1.8 \mathrm{GPa}$ the sample became polycrystalline. Other experiments in which the pressure was increased in small steps, with intensity data collection at each stage gave similar results, with sample deterioration occurring in every case.

A crystal of L-cysteine-I was loaded and compressed in approximately $1.5 \mathrm{GPa}$ steps in quick succession from $0.3 \mathrm{GPa}$ to $4.2 \mathrm{GPa}$. Raman spectra were acquired at each stage, and the pressure increase from 0.3 to $4.2 \mathrm{GPa}$ occurred over $c a$ 90 min, i.e. much more quickly than when the effect of pressure was monitored using X-ray diffraction. At $4.2 \mathrm{GPa}$ the Raman spectrum (Fig. 2), and determination of the unit-cell dimensions, showed that a single-crystal to single-crystal phase transition had taken place to give a previously uncharacterized phase of L-cysteine, which we have designated L-cysteine-III. Single-crystal X-ray diffraction data were collected, with the results shown in Table 1.

The sample was then decompressed to $2.6 \mathrm{GPa}$ and then further to $1.7 \mathrm{GPa}$. Diffraction data collected at $1.7 \mathrm{GPa}$ showed that another single-crystal to single-crystal phase transition had taken place to another previously unchar-

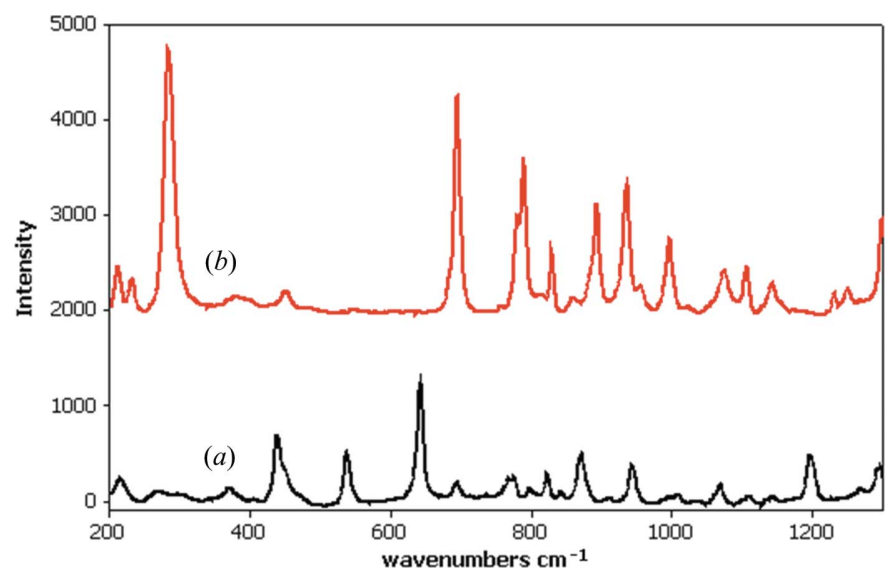

Figure 2

Raman spectra of $(a)$ L-cysteine-I at $0.3 \mathrm{GPa}$ and $(b)$ L-cysteine-III at $4.2 \mathrm{GPa}$ between 0 and $1300 \mathrm{~cm}^{-1}$. 
acterized monoclinic phase, which we have designated Lcysteine-IV (Table 1).

The sample became polycrystalline on further decompression and no further structural data could be extracted.

\subsection{Compression using methanol/ethanol as a hydrostatic medium}

Compression data were collected on L-cysteine-I in approximately $0.7 \mathrm{GPa}$ steps starting at $0.7 \mathrm{GPa}$ using a $4: 1$ mixture of methanol and ethanol as the hydrostatic fluid; Xray diffraction data were collected at each stage. A phase transition from phase I to phase III occurred during data collection; the pressure at the beginning of data collection was 1.7 $\mathrm{GPa}$, but after data collection the pressure was found to have increased to $2.1 \mathrm{GPa}$. Changes in pressure can often fluctuate due to changes in temperature, however, the change in pressure here was thought to change due to the cell still equilibrating during data collection. The time taken for this to occur can vary, as this process is highly dependant on the time taken for the gasket to protrude inwards providing the hydrostatic environment, a process which is difficult to quantify as the deformation of the gasket on increasing pressure cannot be measured. Pressures are measured before and after each diffraction experiment, where the pressure is usually found to vary only slightly by $c a 0.1 \mathrm{GPa}$. This was the case for L-cysteine for all but this particular data collection, with the effect proving fortuitous on this occasion. Further data were collected on L-cysteine-III on increasing pressure further to 2.6 and $3.2 \mathrm{GPa}$.

Data were then collected on backing down in pressure at 2.5 and $1.8 \mathrm{GPa}$. At $1.8 \mathrm{GPa}$ the sample broke up, but it was nevertheless possible to determine the unit-cell dimensions by indexing spots from one of the larger crystallites $[a=8.08$ (3), $b=5.442$ (11), $\left.c=10.63(4) \AA, \beta=93.7(3)^{\circ}\right]$. This showed that the sample was L-cysteine-IV. The sample was then removed from the cell and a small crystallite (crystal dimensions measuring $37.5 \times 12.5 \times 12.5 \mu \mathrm{m}$ ) from the now polycrystalline sample was taken to the SRS Daresbury Laboratory. Single-crystal diffraction data were collected at room temperature with synchrotron radiation $(\lambda=0.6778 \AA)$ on a Bruker APEX-II diffractometer installed on Station 9.8. This experiment showed that on downloading, the sample had returned to phase $\mathrm{I}$.

Data for L-cysteine-I at ambient pressure and $1.8 \mathrm{GPa}$ (medium pentane/isopentane), L-cysteine-III at $2.6 \mathrm{GPa}$ (methanol/ethanol) and 4.2 GPa (pentane/isopentane) and Lcysteine-IV at $1.7 \mathrm{GPa}$ (pentane/isopentane) are included in Table 1.

\subsection{Refinement of the crystal structure of L-cysteine-I at 1.8 GPa}

The data-set used here was that obtained under increasing pressure with pentane/isopentane as the hydrostatic medium. Refinements were carried out against $|F|^{2}$ using all data (CRYSTALS) starting from the coordinates of Kerr et al. (1975). Owing to the low completeness of the data set (57.5\%), all 1, 2 and 1, 3 distances were restrained to the values observed in the ambient-pressure structure. Only the $\mathrm{S}$ atom was refined with anisotropic displacement parameters, while all other non-H atoms were refined isotropically. All $\mathrm{H}$ atoms attached to $\mathrm{N}$ or $\mathrm{C}$ were placed geometrically and not refined; the thiol $\mathrm{H}$ atom was not placed. Listings of crystal and refinement data are given in Table 1.

\subsection{Solution and refinement of L-cysteine-III at 2.6 GPa}

The data set used here was that obtained during the increasing-pressure phase of the experiments carried out with methanol/ethanol as the hydrostatic medium. We have chosen to discuss these data in detail because they were obtained under the conditions which were closest to those of the highest-pressure study on phase I.

The structure of L-cysteine-III was solved by direct methods (SIR92; Altomare et al., 1994). The setting used was chosen to facilitate comparisons with L-cysteine-I. Refinement procedures were the same as those described for L-cysteine-I at $1.8 \mathrm{GPa}$. All $\mathrm{H}$ atoms attached to $\mathrm{N}$ or $\mathrm{C}$ were placed geometrically and not refined.

The position of $\mathrm{H} 1$, the $\mathrm{H}$ atom attached to sulfur, was located in a difference map based on phases calculated using refined positions for all other atoms in the structure. The highest electron-density difference peak was $1.49 \AA$ from S1 in a staggered position between $\mathrm{H} 2$ and $\mathrm{C} 2$. Assignment of this peak as $\mathrm{H} 1$ followed by free refinement yielded $d(\mathrm{~S} 1-\mathrm{H} 1)=$ $1.24 \AA, \angle(\mathrm{C} 10 \mathrm{~S} 1-\mathrm{H} 1)=93^{\circ}$ and $U_{\text {iso }}(\mathrm{H} 1)=0.08 \AA^{2}$, while reducing $R 1$ by $0.2 \%$. The $\mathrm{S}-\mathrm{H}$ distance was restrained to 1.33 (1) $\AA$ in subsequent cycles of least squares. The two possible alternative positions for $\mathrm{H} 1$, staggered between $\mathrm{H} 2$ and $\mathrm{H} 3$ or $\mathrm{C} 2$ and $\mathrm{H} 3$, make contacts of 1.6 and $1.7 \AA$ to $\mathrm{H}$ atoms in neighbouring molecules, therefore making these choices for the position of H1 unfavourable.

Listings of crystal and refinement data are given in Table 1.

\subsection{Solution and refinement of L-cysteine-IV at 1.7 GPa}

The data set used here was that obtained during the decreasing pressure phase of the experiments carried out with pentane/isopentane as the hydrostatic medium. The data set was of poor quality with broad, irregular reflection peak shapes; indexing was achieved after manual selection of diffraction spots. After integration $R_{\text {int }}$ was 0.166 in point group 2 and, in spite of numerous attempts, this is the best data set that we ever obtained. L-Cysteine-IV is monoclinic $P 2_{1}$ with a volume implying $Z^{\prime}=2$. Structure solution was attempted using direct methods, Patterson methods and global optimization, but all failed to yield a recognisable structure.

The unit-cell dimensions of L-cysteine-IV are $a=8.13, b=$ 5.44, $c=10.91 \AA$ and $\beta=95^{\circ}$; the corresponding (transformed) values for L-cysteine-I are rather similar at 8.11, 5.42 and $12.16 \AA, \beta=90^{\circ}$, and it seemed probable that the two structures were similar. A model of the structure of the L-cysteineIV was prepared from the coordinates of L-cysteine-I; the space group was changed to $P 2_{1}$ with two previously symmetry-equivalent molecules comprising the asymmetric 
Table 2

Torsion angles $\left({ }^{\circ}\right)$ in L-cysteine as a function of pressure.

For L-cysteine-IV, (1) and (2) refers to each symmetry independent molecule as referred to in the text

\begin{tabular}{|c|c|c|c|c|c|c|}
\hline Pressure $(\mathrm{GPa})$ & 0 & 1.8 & 2.6 & 4.2 & 1.7 & 1.7 \\
\hline Phase & I & I & III & III & $\operatorname{IV}(1)$ & $\operatorname{IV}(2)$ \\
\hline $\begin{array}{l}\mathrm{N} 1-\mathrm{C} 2-\mathrm{C} 1-\mathrm{S} 1 \\
\mathrm{~N} 1-\mathrm{C} 2-\mathrm{C} 3-\mathrm{O} 2\end{array}$ & $\begin{array}{r}65.32(13) \\
-16.96(19)\end{array}$ & $\begin{array}{c}57.2(7) \\
-23.6(10)\end{array}$ & $\begin{array}{l}-56.6(7) \\
-26.6(10)\end{array}$ & $\begin{array}{l}-57.3(5) \\
-20.6(8)\end{array}$ & $\begin{array}{l}-67(2) \\
-45(3)\end{array}$ & $\begin{array}{l}71.3(18) \\
1(4)\end{array}$ \\
\hline
\end{tabular}

unit. The $\mathrm{S}$ atoms were deleted and then relocated in a difference synthesis calculated on the phases based on the $\mathrm{C}$, $\mathrm{N}$ and $\mathrm{O}$ positions.

The molecules were initially treated as rigid groups during refinement, but these constraints were later relaxed, and 1, 2 and 1, 3 distances were restrained to values in L-cysteine-I. The program ROTAX (Cooper et al., 2002) indicated that the sample was non-merohedrally twinned via an approximate twofold axes about [100]; twinning was anticipated because the crystal had been formed in a phase transition from the higher-symmetry phase III. The twin law matrix was

$$
\left(\begin{array}{ccc}
1 & 0 & 0 \\
0 & -1 & 0 \\
-0.23 & 0 & -1
\end{array}\right) .
$$

The data were then reintegrated with both twin components simultaneously using the program $S A I N T$, and an absorption correction was applied with $S H A D E$ and TWINABS (Sheldrick, 2004b).

Restrained refinement was carried out against $F$ using data with $F>4 \sigma(F)$. Common isotropic displacement parameters were refined for the $\mathrm{C}, \mathrm{N}$ and $\mathrm{O}$ atoms in each of the two molecules in the asymmetric unit; isotropic displacement parameters were also refined for each of the two $\mathrm{S}$ atoms. $\mathrm{H}$ atoms attached to $\mathrm{C}$ and $\mathrm{N}$ were placed geometrically and not refined. $\mathrm{H}$ atoms attached to both $\mathrm{S}$ atoms were not placed as these $\mathrm{H}$ atoms could not be located in a difference map. The twin scale factor refined to $0.476(11)$. Although it is commensurate with $R_{\text {int }}$, the $R$ factor is high at $14 \%$ and the solution we present here should be regarded as rather tentative.

Listings of crystal and refinement data are given in Table 1.

\subsection{L-Cysteine-I at 0.5 GPa studied by single-crystal neutron diffraction}

We show in $\S 3$ that one effect of compression of L-cysteine-I is a substantial shortening of the S...S distances. Neutron diffraction data were collected with the aim of characterizing the behaviour of the thiol H-atom.

Neutron diffraction data were collected on Station SXD (Keen et al., 2006) at the ISIS neutron spallation source, Didcot, UK. Three crystals were fixed at random orientations on $\mathrm{Al}$ tape and mounted inside a null-scattering $\mathrm{Ti} / \mathrm{Zr}$ cell. The assembly was pressurized to $0.5 \mathrm{GPa}$ using He gas resulting in a uniform, hydrostatic pressure. Data were collected at room temperature at three orientations whereby the cell/crystal assembly was rotated successively by $30^{\circ}$ around the vertical axis. Data from the three crystals were processed using locally available software (SXD2001; Gutmann, 2005) and corrected for absorption within the same program.

A difference synthesis was calculated using phases based on all atoms except for the thiol $\mathrm{H}$ atom, the model being taken from Kerr et al. (1975). Amongst the most prominent features in the map were two holes (depths -0.91 and $-0.67 \mathrm{fm} \AA^{-3}$ ) located either side of the $\mathrm{S}$ atom at a distance of $c a 1.3 \AA$. These were included in the model as two part-weight $\mathrm{H}$ atoms. The $\mathrm{S}-\mathrm{H}$ distances were restrained to be 1.33 (1) $\AA$ and a common isotropic displacement parameter was refined for the two atoms. When at site $\mathrm{H} 1$ the $\mathrm{H}$ atom forms an $\mathrm{SH}$... S contact; when at site $\mathrm{H} 10$ it forms a contact to a neighbouring $\mathrm{O}$ atom (see below). The occupancies were also refined. Anisotropic displacement parameters (a.d.p.s) were refined for all non- $\mathrm{H}$ atoms using global rigid-bond and rigid-body restraints; the $\mathrm{NH}_{3}^{+}, \mathrm{CH}$ and $\mathrm{CH}_{2}$ moieties were treated as variable metric rigid groups with common isotropic displacement parameters. The occupancies of $\mathrm{H} 1$ and $\mathrm{H} 10$ refined to 0.53 (4) and 0.47 (4), and the final $R$ factor based on 213/341 unique data to $0.8 \AA$ with $F>4 \sigma(F)$ was 0.0786 . The $\mathrm{S}$ atom adopts a somewhat prolate a.d.p. (principal values: 0.1097, 0.0535 and 0.0135 ); this was interpreted by Kerr et al. (1975) as indicative of disorder in the $\mathrm{S}$ position, induced by the $\mathrm{H}$-atom disorder. No attempt was made to model disorder here though. All calculations were carried out using the program SHELXL97 (Sheldrick, 2001).

\subsection{Structure analysis and visualization software}

Crystal structures were visualized using the programs CAMERON (Watkin et al., 1996), DIAMOND (Crystal Impact, 2004), MERCURY (Bruno et al., 2002) and $X P$ (Sheldrick, 1997). Analyses were carried out using PLATON (Spek, 2003), as incorporated in the WIN-GX suite (Farrugia, 1999). Searches of the Cambridge Structural Database (Allen, 2002; Allen \& Motherwell, 2002) were performed with the program CONQUEST and Version 5.26 of the database with updates up to August 2005.

\subsection{2. $A b$ initio calculations}

$A b$ initio calculations were performed with the plane-wave pseudopotential implementation of density functional theory (DFT) using the CASTEP code (Segall et al., 2002), with the aim of further characterizing the behaviour of the thiol $\mathrm{H}$ 
Table 3

Hydrogen-bonding parameters $\left(\AA{ }^{\circ}{ }^{\circ}\right)$ in L-cysteine-I, III and IV in L-cysteine-IV.

(1) and (2) refer to the symmetry-independent molecules.

\begin{tabular}{|c|c|c|c|c|c|c|}
\hline \multirow{3}{*}{$\begin{array}{l}X-\mathrm{H} \cdots Y \\
\text { Phase }\end{array}$} & \multicolumn{6}{|c|}{ Pressure (GPa) } \\
\hline & 0 & 1.8 & 2.6 & 4.2 & 1.7 & 1.7 \\
\hline & I & I & III & III & IV(1) & $\operatorname{IV}(2)$ \\
\hline \multicolumn{7}{|l|}{$\mathrm{N} 1-\mathrm{H} 5 \cdots \mathrm{O} 1^{\mathrm{i}}$} \\
\hline $\begin{array}{l}\mathrm{N} 1 \cdots \mathrm{O} 1 \\
\mathrm{~N} 1-\mathrm{H} 6 \cdots \mathrm{O} 2^{\mathrm{ii}}\end{array}$ & $2.787(2)$ & $2.721(9)$ & $2.724(9)$ & $2.716(6)$ & $2.85(4)$ & $2.69(4)$ \\
\hline $\begin{array}{l}\mathrm{N} 1 \cdots \mathrm{O} 2 \\
\mathrm{~N} 1-\mathrm{H} 7 \cdots \mathrm{O} 2^{\mathrm{iii}}\end{array}$ & $3.017(2)$ & $2.863(11)$ & $2.837(11)$ & $2.817(8)$ & $2.89(5)$ & $2.99(5)$ \\
\hline $\begin{array}{l}\mathrm{N} 1 \cdots \mathrm{O} 2 \\
\mathrm{C} 1-\mathrm{H} 2 \cdots \mathrm{O} 1^{\text {iv }}\end{array}$ & $2.7600(16)$ & $2.715(8)$ & $2.708(8)$ & $2.699(6)$ & $2.73(3)$ & $2.80(3)$ \\
\hline $\begin{array}{l}\mathrm{C} 1 \cdots \mathrm{O} 1 \\
\mathrm{C} 1-\mathrm{H} 3 \cdots \mathrm{O} 1^{\mathrm{v}}\end{array}$ & $3.289(2)$ & $3.241(9)$ & - & - & - & $3.26(3)$ \\
\hline $\begin{array}{l}\mathrm{C} 1 \cdots \mathrm{O} 1 \\
\mathrm{C} 2-\mathrm{H} 4 \cdots \mathrm{O} 2^{\mathrm{vi}}\end{array}$ & $3.839(2)$ & $3.450(10)$ & - & - & - & $3.39(3)$ \\
\hline $\begin{array}{l}\mathrm{C} 2 \cdots \mathrm{O} 2 \\
\mathrm{C} 1-\mathrm{H} 3 \cdots \mathrm{O} 2^{\mathrm{vii}}\end{array}$ & - & - & $3.325(9)$ & $3.220(7)$ & $3.17(3)$ & - \\
\hline $\begin{array}{l}\mathrm{C} 1 \cdots \mathrm{O} 2 \\
\mathrm{~S} 1-\mathrm{H} 10 \cdots \mathrm{O} 2^{\mathrm{viii}}\end{array}$ & - & - & - & - & $3.10(4)$ & $3.43(4)$ \\
\hline $\mathrm{S} 1 \cdots \mathrm{O} 2$ & $3.3788(15)$ & $3.275(7)$ & - & - & - & - \\
\hline $\mathrm{H} 10 \cdots \mathrm{O} 2$ & 2.17 (3) & - & - & - & - & - \\
\hline $\begin{array}{l}\angle \mathrm{S} 1 \mathrm{H} 10 \mathrm{O} 2 \\
\mathrm{~S} 1-\mathrm{H} 1 \cdots \mathrm{S} 1^{\mathrm{ix}}\end{array}$ & $148(3)$ & - & - & - & - & - \\
\hline $\mathrm{S} 1 \cdots \mathrm{S} 1$ & $3.8457(10)$ & $3.450(4)$ & - & - & - & - \\
\hline $\mathrm{H} 1 \cdots \mathrm{S} 1$ & $2.81(4)$ & - & & & & \\
\hline$\angle \mathrm{S} 1 \mathrm{H} 1 \mathrm{~S} 1$ & $133(2)$ & - & - & - & - & - \\
\hline $\mathrm{S} 1-\mathrm{H} 1 \cdots \mathrm{O} 1^{\mathrm{x}}$ & - & - & & & - & - \\
\hline $\mathrm{S} 1 \cdots \mathrm{O} 1$ & & & $3.432(7)$ & $3.373(5)$ & & \\
\hline $\mathrm{H} 1 \cdots \mathrm{O} 1$ & & & $2.49(10)$ & $2.50(8)$ & & \\
\hline$\angle \mathrm{S} 1 \mathrm{H} 1 \mathrm{O} 1$ & & & $125(5)$ & $120(4)$ & & \\
\hline
\end{tabular}

Symmetry codes: for L-cysteine-I and III: (i) $\frac{1}{2}+x, \frac{3}{2}-y, 1-z$; (ii) $\frac{3}{2}-x, 2-y$, $\frac{1}{2}+z$; (iii) $x, y, 1+z$; (v) $1-x,-\frac{1}{2}+y, \frac{3}{2}-z$; (vi) $1-x,-\frac{1}{2}+y$, $\frac{3}{2}-z$; (viii) $\frac{3}{2}-x, 2-y, \frac{1}{2}+z$; (ix) $\frac{1}{2}-x, 2-y,-\frac{1}{2}+z$; (x) $-\frac{1}{2}+x, \frac{3}{2}-y, 1-z$. For L-cysteine-IV, molecule 1 : (i) $1-x, \frac{1}{2}+y, 1-z$; (ii) $1-x,-\frac{1}{2}+y, 1-z$; (iii) $x,-1+y, z$; (vi) $-x, \frac{1}{2}+y, 1-z$; (vii) $1-x,-\frac{1}{2}+y, 1-z$. For L-cysteine-IV, molecule 2: (i) $-x,-\frac{1}{2}+y, 1-z$; (ii) $-x, \frac{1}{2}+y, 2-z$; (iii) $x, 1+y, z$; (iv) $x, 1+y, z$; (v) $1-x,-\frac{1}{2}+y, 1-z$; (vii) $1-x,-\frac{1}{2}+y, 1-z$.

atom in L-cysteine-I. Plane-wave basis sets have many benefits compared with conventionally used quantum chemistry basis sets; in particular, a simple parameter exists, the cut-off energy, to determine the completeness of the basis. This gives us confidence that the wavefunction can describe any properties without bias towards any other particular result (Clark et al., 1998). In our calculations, the many-body exchange and correlation interactions were described using the generalized gradient approximation (Perdew \& Wang, 1992). Such calculations are capable of giving accurate and reliable structural and electronic information. Ultrasoft pseudopotentials (Vanderbilt, 1990) are used to describe the electron-ion interactions. A cut-off energy of $380 \mathrm{eV}$ was used, which converged the total energy of the system to $1.0 \mathrm{meV}$ per molecule. The Monkhorst-Pack $k$-point sampling scheme (Monkhorst \& Pack, 1976) was used to perform the integrations in $k$-space over the first Brillouin zone with the grids for each cell chosen to be dense enough to converge the total energy to $1.0 \mathrm{meV}$ per molecule. For each structure considered the geometry (atomic position and unit-cell parameters) was optimized using a conjugate gradient algorithm. The tolerances used gave energy differences between structures accurate to better than $1.0 \mathrm{meV}$.

\section{Results}

\subsection{Structure of L-cysteine-I at ambient pressure and temperature}

Our motive for discussing the structure of Lcysteine-I here is to highlight structural features that become relevant when analysing the effects of high pressure. The cysteine molecule is in its zwitterionic tautomer. In principle, the $\mathrm{N} 1-\mathrm{C} 2-$ $\mathrm{C} 1-\mathrm{S} 1$ torsion angle $(\chi 1)$ can adopt values of $c a$ $60^{\circ}$ (gauche- ${ }^{+}$or $\left.g^{+}\right),-60^{\circ}\left(g^{-}\right)$and $180^{\circ}$ (trans or $t$ ), although in small molecules there is a strong preference for the $g^{+}$conformation (Görbitz, 1990). In L-cysteine-I, $\chi 1=65.32(13)^{\circ}\left(g^{+}\right.$, Fig. $1 b$, Table 2); in L-cysteine-II $\chi 1=74.40(12)^{\circ}\left(g^{+}\right)$in one molecule and $-170.16(8)^{\circ}(t)$ in the other.

The shortest hydrogen bond (Table 3), $\mathrm{N} 1 \mathrm{H} 7 \cdots \mathrm{O} 2$, lies along $\mathbf{c}$ to form a primary-level $C(5)$ chain (Fig. 3a). The second shortest hydrogen bond, N1H5 ... 1 , links molecules into primary-level $C(5)$ chains, which run perpendicular to the $C(5)$ chains formed by the $\mathrm{N} 1 \mathrm{H} 7 \ldots \mathrm{O} 2$ hydrogen bonds. The combination of these two $C(5)$ chains yields a layer composed of $R_{4}^{4}(16)$ ring motifs (Fig. 3a). The layer is parallel to the $a c$ plane, having a sinusoidal appearance when viewed in projection down c (Fig. 4a; the layers in this figure are indicated with block arrows). The last of the $\mathrm{NH} \cdots \mathrm{O}$ interactions, $\mathrm{N} 1 \mathrm{H} 6 \cdots \mathrm{O} 2$, links the layers together along the $b$ direction (Fig. $4 a$ ). Pairs of N1H6 . . O 2 contacts form a secondarylevel $R_{3}^{2}(9)$ ring motif. (Fig. $5 a$ ).

In L-cysteine-I the thiol $\mathrm{H}$ atom is disordered over two sites, forming either $\mathrm{SH} \cdots \mathrm{S}$ or $\mathrm{SH} \cdots \mathrm{O}$ contacts. The former is slightly preferred (Kerr et al., 1975) and the $\mathrm{SH}$ group becomes ordered in this orientation at $30 \mathrm{~K}$ (Moggach, Clark \& Parsons, 2005). The $\mathrm{S}-\mathrm{H} \cdots \mathrm{S}$ interactions form an infinite hydrogen-bonded chain which zigzags along $\mathbf{c}$ (Fig. 4a), supporting the $R_{3}^{2}(9)$ ring motifs in connecting the sinusoidal layers. The $\mathrm{SH} \cdots \mathrm{O}$ interaction forms a discrete contact to the carboxylate oxygen $(\mathrm{O} 2)$ atom involved in the $R_{3}^{2}(9)$ ring motif.

Under ambient conditions only two $\mathrm{CH} \cdots \mathrm{O}$ interactions are present: $\mathrm{C} 1 \mathrm{H} 2 \cdots \mathrm{O} 1$, which forms a primary $C(6)$ hydrogen-bonded chain that runs along the $c$-axis direction, and $\mathrm{C} 1 \mathrm{H} 3 \ldots \mathrm{O} 1$ which runs parallel with $\mathrm{N} 1 \mathrm{H} 5 \cdots \mathrm{O} 1$. Both of these combine to produce an $R_{4}^{4}(14)$ ring that intertwines within the $R_{4}^{4}(16)$ ring formed by the $\mathrm{NH} \cdots$ O hydrogen bonds (Fig. 3a). A similar motif has been observed in L-cystine (Moggach, Allan, Parsons et al., 2005).

Orthorhombic L-cysteine-I undergoes a phase transition above $1.8 \mathrm{GPa}$.

\subsection{Lattice parameters of L-cysteine-I up to $1.8 \mathrm{GPa}$}

The response of the unit-cell dimensions to pressure is anisotropic, with the most compressible lattice parameter 
between ambient pressure and $1.8 \mathrm{GPa}$ being the $a$ axis, which decreases in length by $8.6 \%$, with the $b$ and $c$ axes shortening by 1.3 and $1.6 \%$, respectively. As the system is orthorhombic, the principal component of the strain tensor is also along the $a$ axis.

\subsection{Intramolecular geometry in L-cysteine-I at $1.8 \mathrm{GPa}$}

Bond distances and angles were restrained during refinement to their ambient pressure values and so no conclusions about their variation with pressure should be drawn from the data reported here. Significant changes do occur in the torsion angles (Table 2), however. Between ambient pressure and 1.8 GPa the NCCS and NCCO torsion angles reduce from $65.32(13)$ to $57.2(7)^{\circ}$ and $-16.96(19)$ to $-23.6(10)^{\circ}$, respectively. It seems likely that these changes occur in order to accommodate the changes in the intermolecular interactions described below.

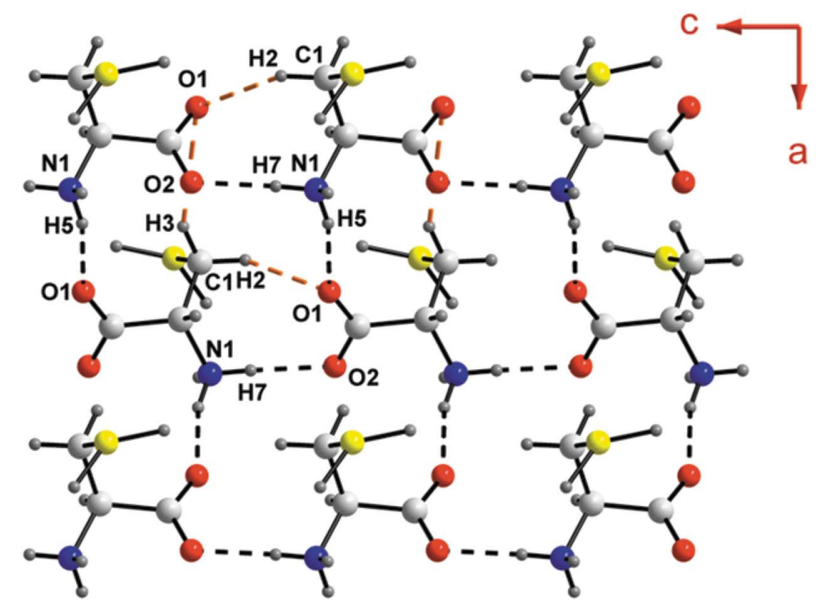

(a)

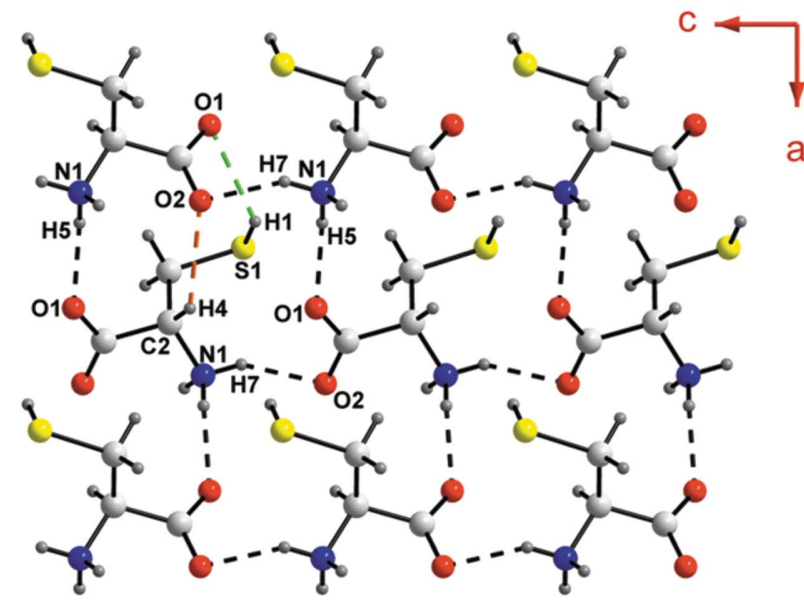

(c)

\subsection{Hydrogen bonds in L-cysteine-I at $1.8 \mathrm{GPa}$}

Variation in hydrogen-bonding parameters between ambient and $1.8 \mathrm{GPa}$ are given in Table $3 . \mathrm{H}$ atoms were placed in idealized positions during refinement and so donorto-acceptor distances $(\mathrm{N} \cdots \mathrm{O})$ rather than $\mathrm{H} \cdots \mathrm{O}$ have been used to quantify the relative compressibility of the hydrogen bonds.

The data in Table 3 (columns 1 and 2) can be summarized as follows; $\Delta$ refers to the $\mathrm{N}$ or $\mathrm{C} \cdot \mathrm{O}$ O distance at ambient pressure minus the corresponding distance at $1.8 \mathrm{GPa}$. The most compressible of the $\mathrm{NH}$... O hydrogen bonds, N1H6 . .O 2, is also the longest $(\Delta=0.15 \AA)$. This hydrogen bond is involved in the $R_{3}^{2}(9)$ motifs that link the sinusoidal layers described above (Fig. 5a). The other hydrogen bond involved in this motif is $\mathrm{N} 1 \mathrm{H} 7 \ldots \mathrm{O} 2$, which is the least compressible of the NH. . O hydrogen bonds $(\Delta=0.05 \AA)$. The last of the $\mathrm{NH} \cdots \mathrm{O}$ hydrogen bonds, N1H5 ..O 1 , is involved in the $R_{4}^{4}(16)$ ring motifs (Fig. $3 a$ and $b$ ); the decrease in the length is only slightly greater than in $\mathrm{N} 1 \mathrm{H} 7 \cdots \mathrm{O} 2(\Delta=$ $0.07 \AA$ ). We note that of the three $\mathrm{NH}$. . O hydrogen-bonding

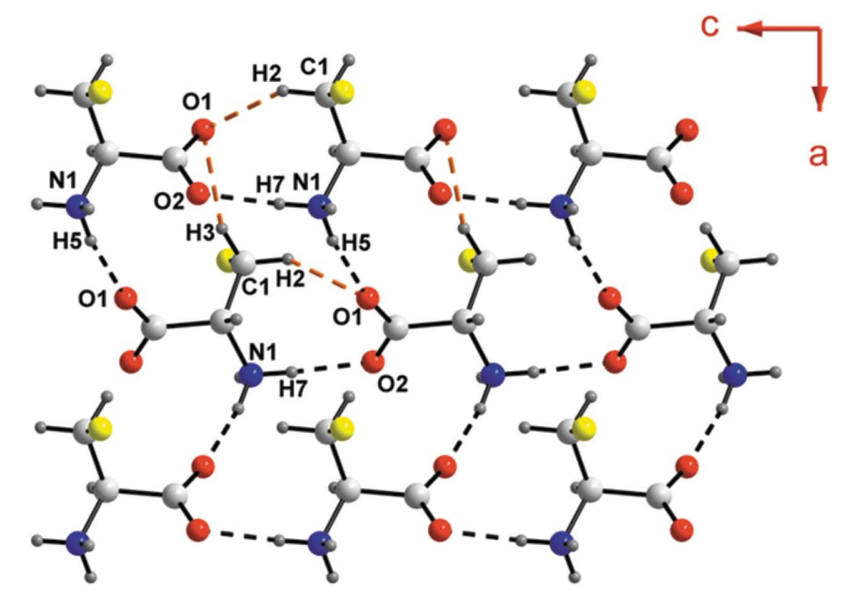

(c)

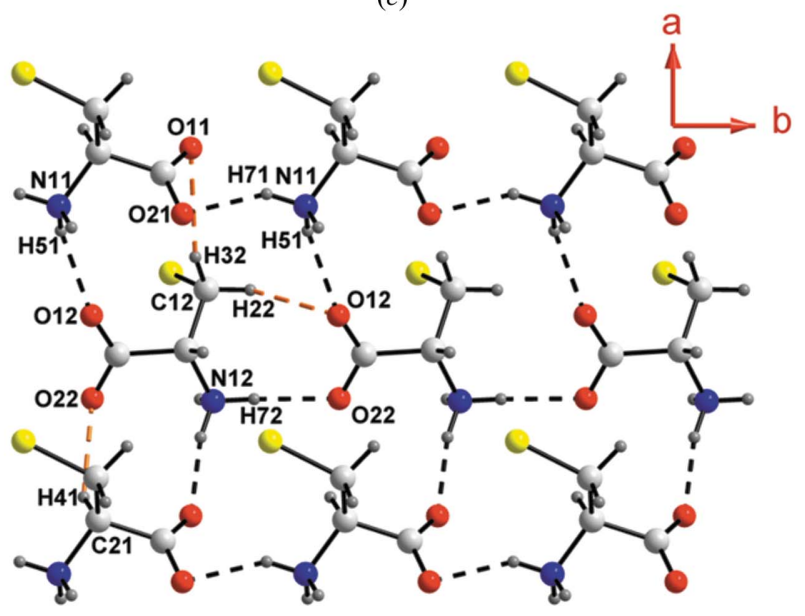

(d)

Figure 3

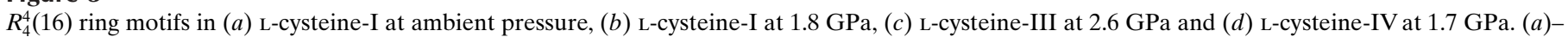

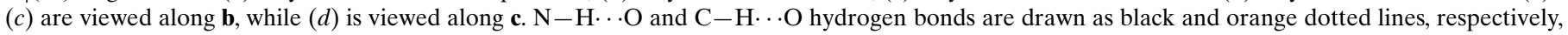

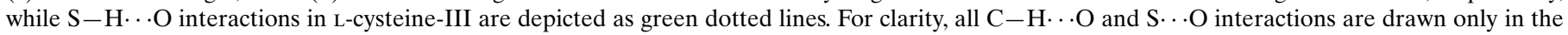
top left quadrant. Colour scheme: yellow S, blue $\mathrm{N}$, red $\mathrm{O}$, grey $\mathrm{C}$ and dark grey $\mathrm{H}$. 
interactions, $\mathrm{N} 1 \mathrm{H} 5 \cdots \mathrm{O} 1$ makes the smallest angle with the $a$ axis (the most compressible crystallographic direction); however, this interaction is not the most compressible $\mathrm{NH} \cdots \mathrm{O}$ hydrogen bond. The compression in $\mathrm{C} 1 \mathrm{H} 3 \cdots \mathrm{O} 1$ is substantially greater $(\Delta=0.39 \AA)$ than in the $\mathrm{NH} \cdots \mathrm{O}$ hydrogen bonds, but the reduction in the length of $\mathrm{C} 1 \mathrm{H} 2 \cdots \mathrm{O} 1$ is more $\operatorname{similar}(\Delta=0.05 \AA)$.

Under ambient conditions the thiol $\mathrm{H}$ atom is disordered over SH..S and SH..O contacts (see above) and it has not been placed in the high-pressure structures reported here.

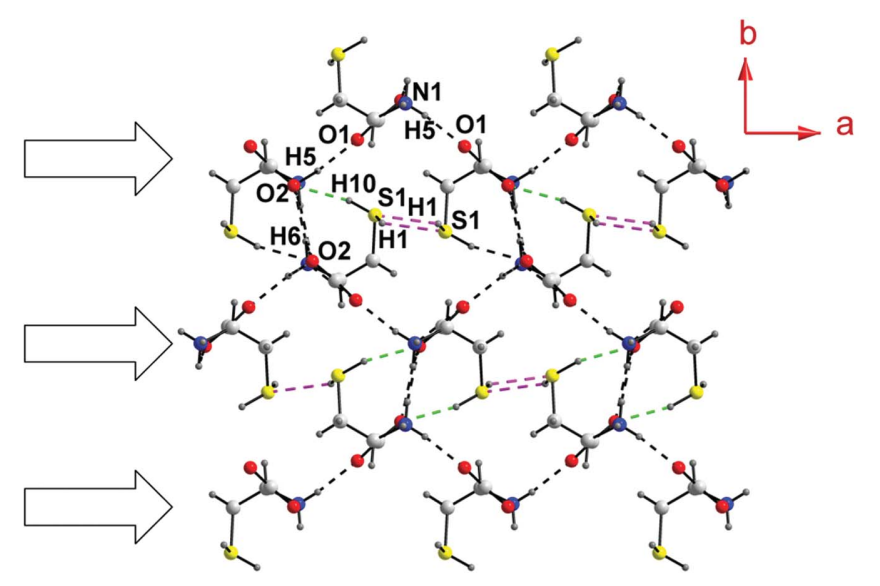

(a)
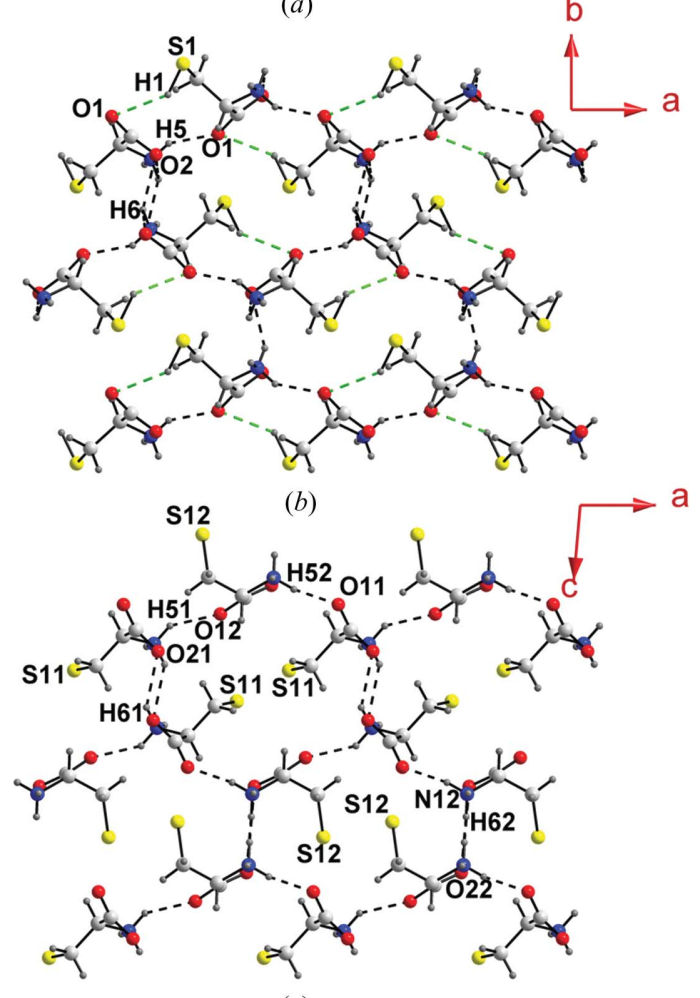

(c)

Figure 4

Unit-cell packing motifs in (a) L-cysteine-I at ambient pressure, $(b) \mathrm{L}-$ cysteine-III at 2.6 GPa and (c) L-cysteine-IV at 1.7 GPa. Both $(a)$ and $(b)$ are viewed along $\mathbf{c}$, while $(c)$ is viewed along $\mathbf{b}$. Note the sinusoidal appearance of $R_{4}^{4}(16)$ ring motifs along $\mathbf{a}$, as indicated by arrows in $(a)$. $\mathrm{NH} \cdots \mathrm{O}, \mathrm{SH} \cdots \mathrm{S}$ and $\mathrm{SH} \cdots \mathrm{O}$ hydrogen bonds are depicted as black, pink and green dotted lines, respectively.
While the S...O distance reduces in length by $0.10 \AA$, the $\mathrm{S}$...S contact is much more compressible, decreasing in length by $0.40 \AA$. This is one of the most compressible interactions in the structure decreasing in length by $8.70 \%$. At $1.8 \mathrm{GPa}$ the $\mathrm{S}$...S distance is 3.450 (4) $\AA$, well within twice the van der Waals radius of S (3.6 ̊; Bondi, 1964).

\subsection{L-Cysteine-I at 0.5 GPa as studied by single-crystal neutron diffraction}

The changes in the geometry about the $\mathrm{S}$ atom led us to speculate that the thiol $\mathrm{H}$ atom may become ordered at elevated pressures. Neutron diffraction data were collected using a gas pressure cell on station SXD at ISIS; the maximum operating pressure of this cell is $0.5 \mathrm{GPa}$. It was clear that at $0.5 \mathrm{GPa}$ the $\mathrm{H}$ atom is still disordered; the occupancies of both $\mathrm{SH}$...S and SH... H atoms refined to 0.53 (4) and 0.47 (4), respectively (Fig. 1b).

\subsection{L-Cysteine-III at $2.6 \mathrm{GPa}$}

The transition from L-cysteine-I to L-cysteine-III occurs at above $1.8 \mathrm{GPa}$. The effect of the transition on the sample depended on the hydrostatic medium being used. In 4:1 methanol-ethanol the transition proceeded smoothly during data collection from one well formed crystalline form to another. In pentane-isopentane an incremental increase of pressure caused the sample to break up or develop high mosaic spread; this could be avoided by increasing the pressure more rapidly in larger steps to $c a 4 \mathrm{GPa}$. Here we discuss the data obtained for L-cysteine-III at $2.6 \mathrm{GPa}$ derived from data obtained using methanol-ethanol; intermolecular contact data are collected in Table 3.

There is a significant conformational difference between the cysteine molecules in phases I and III (Fig. $1 b$ and $c$ ). In phase I the molecules adopt the $g^{+}$conformation, with $\tau(\mathrm{N} 1-\mathrm{C} 2-$ $\mathrm{C} 1-\mathrm{S} 1)=57.2(7)^{\circ}$ at $1.8 \mathrm{GPa}$. In phase III the molecules adopt the much less common $g^{-}$conformation, with a corresponding torsion angle of $-56.6(7)^{\circ}$ at $2.6 \mathrm{GPa}$ (Table 2 ). The $\mathrm{N} 1-\mathrm{C} 2-\mathrm{C} 3-\mathrm{O} 2$ torsion angle changes slightly from $-24.9(10)^{\circ}$ in phase I at $1.8 \mathrm{GPa}$ to $-26.6(10)^{\circ}$ in phase III at $2.6 \mathrm{GPa}$. Interestingly, on increasing pressure further to 4.2 $\mathrm{GPa}$, the trend is reversed with the torsion angle adopting a value of $-20.6(8)^{\circ}$. The thiol $\mathrm{H}$ atom is ordered at $2.6 \mathrm{GPa}$, with $\tau(\mathrm{C} 2-\mathrm{C} 1-\mathrm{S} 1-\mathrm{H} 1)=-66(3)^{\circ}$.

The fact that the phase I to III transition proceeds from one single-crystal form to another indicates that the topology of the two forms is likely to be very similar. This proves to be the case and much of the description given above for L-cysteine-I also applies to L-cysteine-III. The structure consists of rows of molecules linked into $C(5)$ chains along $\mathbf{c}$ by $\mathrm{N} 1-\mathrm{H} 7 \cdots \mathrm{O} 2$ hydrogen bonds. These chains are linked into a layer by N1H5...O1 hydrogen bonds, the two types of hydrogen bond combining to form a secondary-level $R_{4}^{4}(16)$ motif (Fig. 3c). The layers are less sinusoidal in cross-section than in phase I, but they are still connected along the $\mathbf{b}$ direction by $\mathrm{N} 1-$ $\mathrm{H} 6 \cdots \mathrm{O} 2$ hydrogen bonds, which combine with $\mathrm{N} 1-\mathrm{H} 7 \cdots \mathrm{O} 2$ hydrogen bonds to form $R_{3}^{2}(9)$ rings (Fig. $5 c$ ). 
Whereas in L-cysteine-I SH..O and SH..S interactions connected the layers, in phase III S1H1 . . O 1 interactions are formed across the $R_{4}^{4}(16)$ rings (Fig. 3c). At 3.433 (7) $\AA$ the $\mathrm{S}$...O distance is longer than the $\mathrm{SH} \cdots \mathrm{O}$ contact observed in L-cystine-I at $1.8 \mathrm{GPa}$. $\mathrm{C} 2 \mathrm{H} 4 \cdots \mathrm{O} 2$ contacts are also formed across the $R_{4}^{4}(16)$ rings to the same carboxylate group as is involved in the SH ..O interaction. In phase I H4 was not involved in hydrogen-bonding interactions, even though this $\alpha-\mathrm{H}$ atom is often regarded as being activated towards hydrogen bonding by the neighbouring ammonium and carboxylate groups (Derewenda et al., 1995). The final weak interaction worthy of comment is $\mathrm{C} 1 \mathrm{H} 2 \cdots \mathrm{S} 1$, which supports the $\mathrm{N} 1 \mathrm{H} 6 \ldots . . \mathrm{O} 2$ hydrogen bonds which connect the layers along the $\mathbf{b}$ direction. There are no S...S contact distances within $3.6 \AA$.

\subsection{L-Cysteine-IV at 1.7 GPa}

L-Cysteine-IV, which crystallizes in the monoclinic space group $P 2_{1}$, was formed in a single-crystal to single-crystal phase transition on decompression of phase III. The diffraction data were of low quality and the transition from orthorhombic to monoclinic symmetry resulted in twinning. Nevertheless, the broad structural characteristics of this phase can be discerned, albeit with some disclaimers: caution should be exercised because the data were poor and the $R$ factor high. There are two molecules in the asymmetric unit. Molecule 1, containing S11 etc., adopts an $\mathrm{N} 11-\mathrm{C} 21-\mathrm{C} 11-\mathrm{S} 11$ torsion angle of $-67(2)^{\circ}$, while in molecule 2 the corresponding angle is $71.0(18)^{\circ}$. The first of these corresponds to the conformation observed in L-cysteine-III, and the second to that found in L-cysteine-I. The $\mathrm{N} 1-\mathrm{C} 2-\mathrm{C} 3-\mathrm{O} 2$ torsion angles also differ

in the two molecules, adopting values of $-45(3)$ and $1(4)^{\circ}$ in molecules 1 and 2, respectively, and these compare with values of $-26.5(10)$ and $-23.6(10)^{\circ}$ in phases III at $2.6 \mathrm{GPa}$ and I at $1.8 \mathrm{GPa}$, respectively.

The crystal structure contains rows of molecules related by lattice repeats along b (Fig. 3d). Alternate rows contain molecules 1 or 2 , connected by $\mathrm{N} 11 \mathrm{H} 71 \cdots \mathrm{O} 21$ or $\mathrm{N} 12 \mathrm{H} 72 \cdots \mathrm{O} 22$ hydrogen bonds. These rows are connected into a layer by $\mathrm{N} 11 \mathrm{H} 51 \cdots \mathrm{O} 12$ and $\mathrm{N} 12 \mathrm{H} 52 \cdots \mathrm{O} 11$ hydrogen bonds, forming $R_{4}^{4}(16)$ rings. The layers are connected by pairs of $\mathrm{N} 11 \mathrm{H} 61 \cdots \mathrm{O} 21$ or $\mathrm{N} 12 \mathrm{H} 62 \cdots \mathrm{O} 22$ hydrogen bonds, which form $R_{3}^{2}(9)$ motifs (Figs. $5 d$ and $e$ ). Packing between the layers connected by N11H61 ‥O2 21 bonds strongly resembles that in L-cysteine-III ( $c f$. Figs. $4 c$ and $b$ ), while packing between the layers connected by $\mathrm{N} 12 \mathrm{H} 62 \cdots \mathrm{O} 22$ hydrogen bonds resembles that in L-cysteine-I ( $c f$. Figs. $4 c$ and $a$ ).

On further decrease in pressure the sample became polycrystalline and no structural data could be extracted. The sample was downloaded from the high-pressure cell, and diffraction data collected with synchrotron radiation using a small crystallite from the now polycrystalline sample. Determination of the unit-cell dimensions and structure solution confirmed that the sample had returned to the ambient pressure L-cysteine-I phase.

\section{Discussion}

\subsection{Anisotropic compression of L-cysteine-I at $1.8 \mathrm{GPa}$}

In previous studies of L-serine, L-cystine and $\alpha$-glycine, we have ascribed the compressibility of intermolecular interactions to closing up of voids which exist, for example, at the centres of $R$-type hydrogen-bond motifs. In
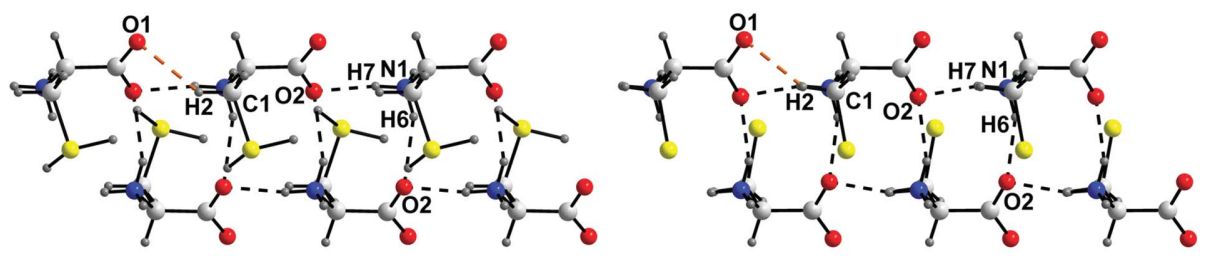

(b)

(a)

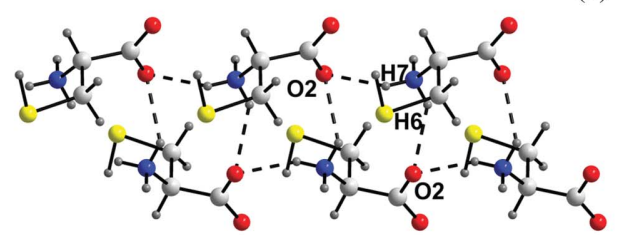

(c)

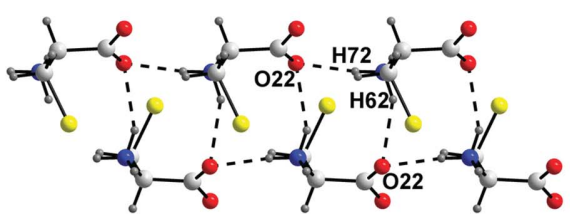

(d)

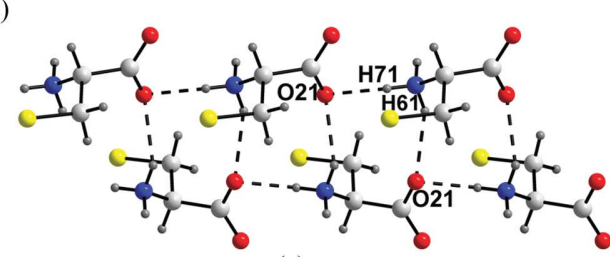

(e)
Figure 5

On the following page. $R_{3}^{2}(9)$ ring motifs in $(a)$ L-cysteine-I at ambient pressure, $(b)$ L-cysteine-I at $1.8 \mathrm{GPa},(c)$ Lcysteine-III at 2.6 GPa, and $(d)$ and $(e)$ L-cysteine-IV at $1.7 \mathrm{GPa}$. Hydrogen bonds and colour scheme as in Fig. 3. L-cysteine-I the relative compressibility of intermolecular interactions can also be analysed in this way.

Comparison of spacefilling plots of $R_{4}^{4}(16)$ ring motifs at ambient pressure and $1.8 \mathrm{GPa}$ clearly illustrate the closing-up of holes within these motifs (Figs. $6 a$ and $b$ ). The secondary-level $\quad R_{4}^{4}(16)$ rings comprise two rows of molecules, consisting of primary-level $C(5)$ chains built by $\mathrm{N} 1 \mathrm{H} 7 \ldots \mathrm{O} 2$ hydrogen bonds formed along the $c$ axis direction (Fig. 3a). Under pressure, alternate rows shift along the positive and negative $c$ directions ( $c f$. Figs. $3 a, b$ 
and 7). This sliding movement enables the voids to close up perpendicular to the $c$ direction. A similar effect was observed in L-serine, although in that case the sliding of the rows occurred abruptly and resulted in a phase transition.

Although the sliding of the rows of molecules contracts the voids in the $R_{4}^{4}(16)$ rings, the $\mathrm{N}-\mathrm{H} \cdots \mathrm{O}$ interactions around the perimeter of the rings are not greatly affected, and $\mathrm{N} \cdots \mathrm{O}$ separations in $\mathrm{N} 1 \mathrm{H} 5 \cdots \mathrm{O} 1$ and $\mathrm{N} 1 \mathrm{H} 7 \cdots \mathrm{O} 2$ decrease by only 0.06 and $0.05 \AA$, respectively. We note in passing that the headto-tail $\mathrm{N} 1 \mathrm{H} 7 \cdots \mathrm{O} 2$ interaction is characteristic of many amino acid structures; we have studied its response to pressure in Lserine, L-cystine and $\alpha$-glycine, and it is always amongst the least compressible of the $\mathrm{NH}$... O hydrogen bonds.

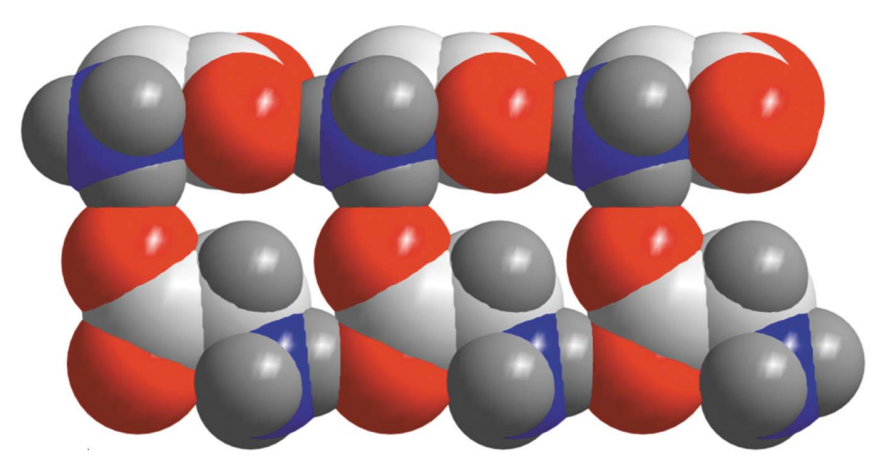

(a)

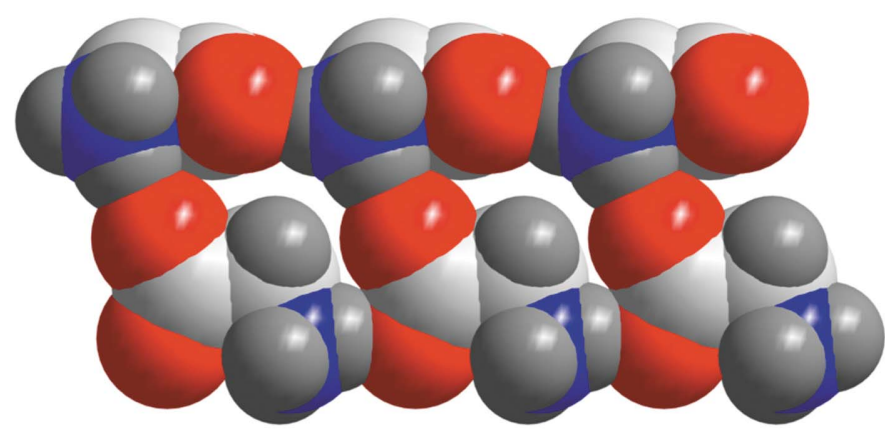

(b)

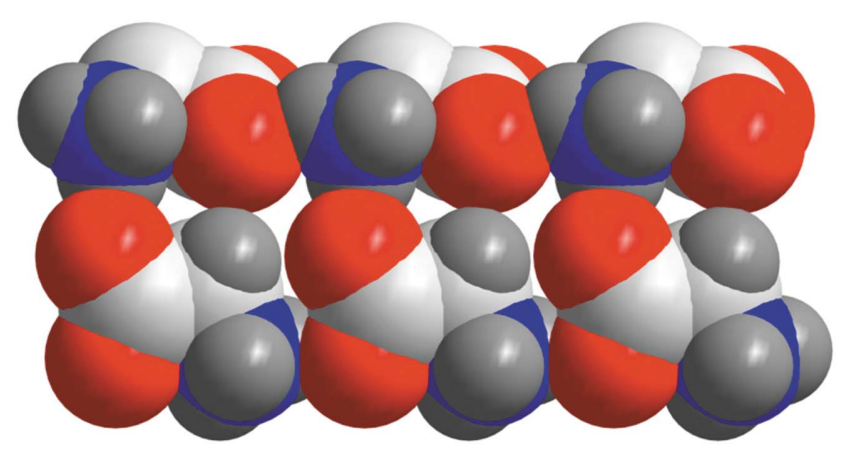

(c)

Figure 6

Space-filling plots showing $R_{4}^{4}(16)$ ring motifs of (a) L-cysteine-I at ambient pressure, $(b)$ L-cysteine-I at $1.8 \mathrm{GPa}$ and $(c)$ L-cysteine-III at $2.6 \mathrm{GPa}$. Note the hole in the middle of the ring becomes progressively smaller on going from $(a)$ to $(c)$. In all three diagrams, the $-\mathrm{CH}_{2} \mathrm{SH}$ group has been removed for clarity.
$\mathrm{C} 1 \mathrm{H} 2 \cdots \mathrm{O} 1$, which, like $\mathrm{N} 1 \mathrm{H} 7 \cdots \mathrm{O} 2$, is formed approximately along the $c$ direction, reduces in length by $0.05 \AA$. The $\mathrm{C} 1 \mathrm{H} 3$...O 1 contact, by contrast, becomes shorter by a much greater amount $(0.39 \AA)$ and this can be traced to the direction in which this contact is formed relative to the direction in which the void closes (Figs. $3 a, b$ and 7).

A space-filling plot of the $R_{3}^{2}(9)$ ring motifs in L-cysteine-I at ambient pressure (Fig. $8 a$ ) shows that, although the voids are present at the centres of these rings, they are substantially smaller than those which exist in the $R_{4}^{4}(16)$ rings (Fig. $6 a$ ). Some modest compression of these voids occurs at $1.8 \mathrm{GPa}$, largely through shortening of the $\mathrm{N} 1 \mathrm{H} 6 \cdots \mathrm{O} 2$ hydrogen bonds. With an N ...O separation of 3.017 (2) $\AA$ at ambient pressure these hydrogen bonds are the longest such interactions in Lcysteine-I and relatively long by the standards of amino acids in general. It is, perhaps, not surprising that $\mathrm{N} 1 \mathrm{H} 6 \cdots \mathrm{O} 2$ hydrogen bonds are the most compressible of this type of interaction, reducing in length by $0.15 \AA$.

The thiol group is disordered in the crystal structure of $\mathrm{L}$ cysteine-I at room temperature. Different components of the disorder led to the formation of $\mathrm{SH} \cdots \mathrm{O}$ and $\mathrm{SH} \cdots \mathrm{S}$ hydrogen bonds, but the latter is marginally favoured. This result is consistent with the results of DFT calculations, which place the $\mathrm{SH} \cdots \mathrm{S}$ structure $4.11 \mathrm{~kJ} \mathrm{~mol}^{-1}$ lower in energy. The shortening of the contacts made around the $\mathrm{S}$ atom might imply that ordering of this site occurs. At $1.0 \mathrm{GPa}$, however, the difference in energy between $\mathrm{S} 1 \mathrm{H} 1 \ldots \mathrm{S} 1$ and $\mathrm{S} 1 \mathrm{H} 1 \cdots \mathrm{O} 2$ models decreases to $3.94 \mathrm{~kJ} \mathrm{~mol}^{-1}$. Moreover, single-crystal neutron diffraction data at $0.5 \mathrm{GPa}$ show that the disorder of the thiol $\mathrm{H}$ atom is not significantly different to that observed at ambient pressure. Such information as we have available therefore tends to support the retention of disorder in Lcysteine-I at elevated pressure.

Interpretation of the changes in contacts involving the $\mathrm{S}$ atoms is difficult because of the disorder of the $\mathrm{H}$ site in the thiol group. For example, analysis of the structure in terms of void distributions is not possible unless all atomic positions

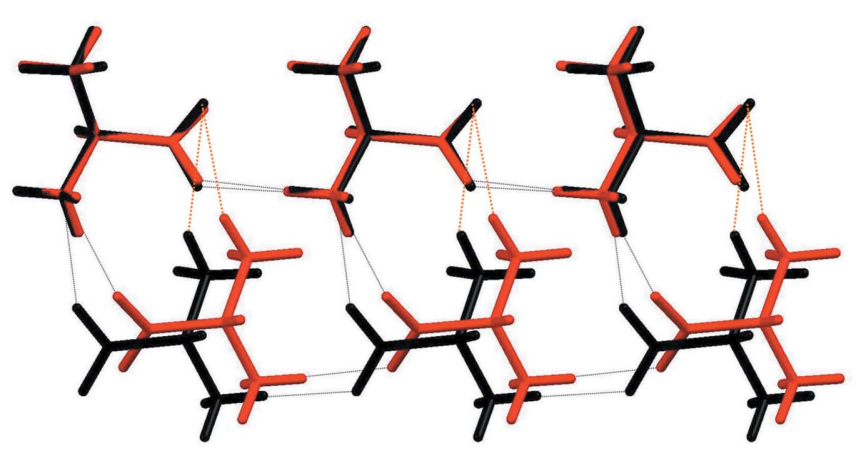

Figure 7

Superposition of the $R_{4}^{4}(16)$ ring motifs of L-cysteine-I at ambient pressure (black) and $1.8 \mathrm{GPa}$ (red). $\mathrm{N}-\mathrm{H} \cdots \mathrm{O}$ hydrogen bonds are drawn as black dotted lines. Note the sliding movement of the layers that comprise the ring motifs over each other and a shortening of the $\mathrm{C} 1-$ $\mathrm{H} 3$.. O 1 contact (orange dotted line) on increasing pressure as a result. 
have been modelled. It is possible, though, to draw some conclusions on the basis of the S...O and S...S distances.

In L-cysteine-II at $120 \mathrm{~K}$ the thiol group is ordered, with one molecule forming an $\mathrm{SH} \cdots \mathrm{O}$ hydrogen bond with $d(\mathrm{~S} \cdots \mathrm{O})=$ 3.404 (1) $\AA$, while the other is involved in an SH...S interaction with $d(\mathrm{~S} \cdots \mathrm{S})=4.080$ (1) $\AA$. More generally, although data are rather sparse, $\mathrm{S} \cdots \mathrm{O}$ distances in $\mathrm{SH} \cdots \mathrm{O}$ hydrogen bonds typically fall into the range 3.3-3.6 $\AA$, whereas S...S distances in SH..S hydrogen bonds are usually ca $4 \AA$ (Desiraju \& Steiner, 1999).

Even at ambient pressure, therefore, the $\mathrm{S} \cdots \mathrm{O}$ and $\mathrm{S} \cdots \mathrm{S}$ distances, $3.3788(15)$ and $3.8457(10) \AA$, are quite short (particularly the latter). At $1.8 \mathrm{GPa}$ the $\mathrm{S}$...O distance [3.280 (6) $\AA$ ] approaches the lower limit for SH . . O interactions determined at ambient pressure. The S ...S distance becomes very short indeed [3.451 (4) $\AA$ ] by comparison with other SH $\cdots$ S hydrogen bonds. By contrast, a search of the Cambridge Structural Database shows that the shortest $\mathrm{N}$... O and $\mathrm{C} \cdots \mathrm{O}$ distances observed under ambient conditions in amino acids are 2.6 and $3.0 \AA$; none of the $\mathrm{N} \cdots \mathrm{O}$ or $\mathrm{C} \cdots \mathrm{O}$

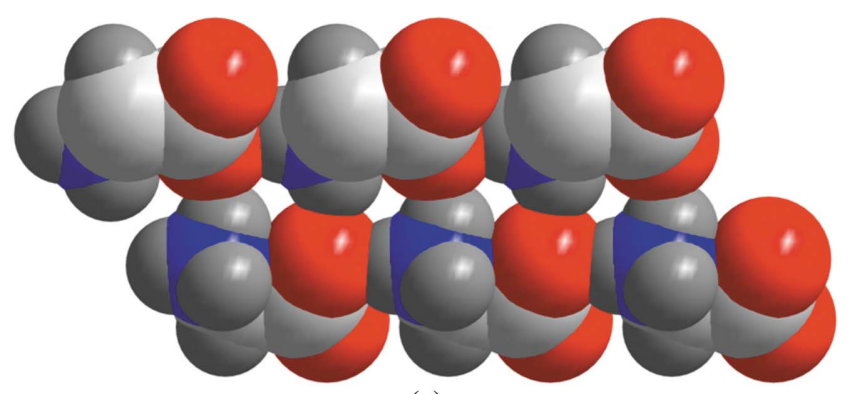

(a)

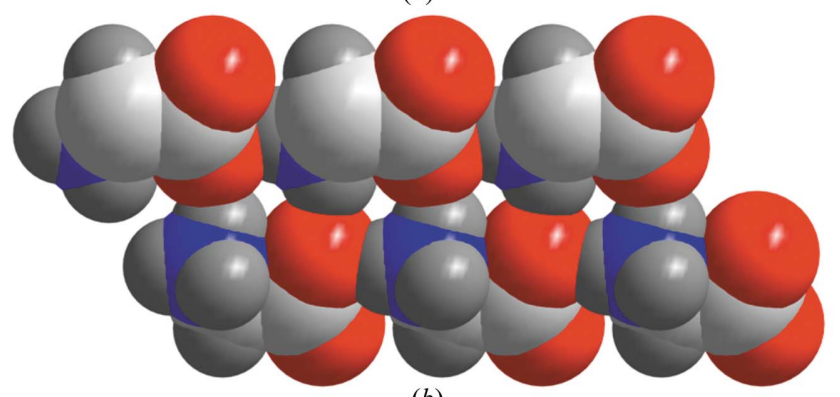

(b)

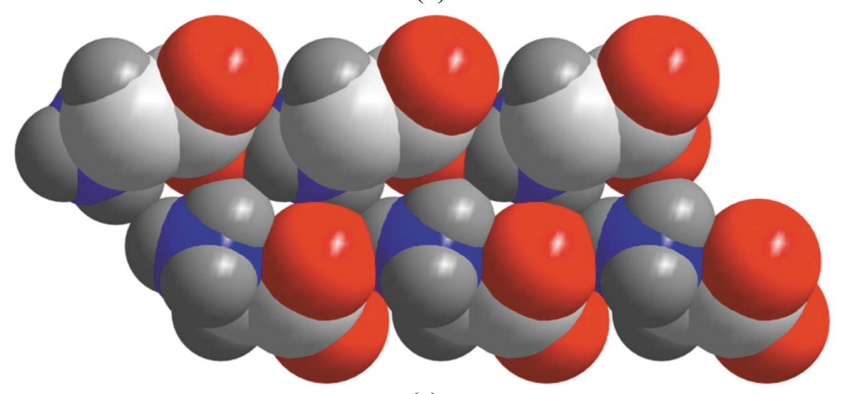

(c)

Figure 8

Space-filling plots showing $R_{3}^{2}(9)$ ring motifs of (a) L-cysteine-I at ambient pressure, $(b)$ L-cysteine-I at $1.8 \mathrm{GPa}$ and $(c)$ L-cysteine-III at $2.6 \mathrm{GPa}$ all viewed perpendicular to the $a$ axis. Note the hole in the middle of the ring motifs becomes progressively smaller on going from $(a)$ to $(c)$. In all three diagrams, the $-\mathrm{CH}_{2} \mathrm{SH}$ group has been removed for clarity. distances observed at $1.8 \mathrm{GPa}$ in L-cysteine-I approach these values.

We have observed that on increasing pressure to $c a 2 \mathrm{GPa}$, a single-crystal to single-crystal phase transition occurs to a hitherto uncharacterized phase of L-cysteine, which we have designated L-cysteine-III. The shortness of the contacts made around the $\mathrm{S}$ atom at $1.8 \mathrm{GPa}$ implies that the system has become quite strained and it seems plausible to suggest that the phase transition is driven by the need to relieve strain around the $\mathrm{S}$ atom.

\subsection{L-Cysteine-III}

The transition from L-cysteine-I to L-cysteine-III was observed during data collection between 1.7 and $2.1 \mathrm{GPa}$. This observation is significant because it shows that on compression phase I transforms directly to phase III without going via an intermediate phase; the reverse statement does not apply on decompression (see below).

There are numerous similarities between L-cysteine-III and L-cysteine-I: for example, both contain $R_{4}^{4}(16)$ ring motifs arranged in layers, which are linked by $R_{3}^{2}(9)$ rings. The change from the $g^{+}$to the $g^{-}$conformation during the transition is accompanied by an alteration in the pattern of weaker $\mathrm{SH} \cdots \mathrm{O}$ and $\mathrm{CH} \cdots \mathrm{O}$ contacts. The strained environment about the $\mathrm{S}$ atom of phase I at $1.8 \mathrm{GPa}$ (noted above) appears to have been relieved and although the pressure is higher, the distances involving $\mathrm{S}$ are all longer in phase III.

Space-filling plots of the $R_{4}^{4}(16)$ and $R_{3}^{2}(9)$ ring motifs in Lcysteine-I and III are compared in Figs. 6 and 8, and it is clear that the voids at the centres of these motifs have closed up significantly in the course of the phase transition. Between ambient pressure and $1.8 \mathrm{GPa}$ the $R_{4}^{4}(16)$ and $R_{3}^{2}(9)$ rings both contract, but these contractions also act to decrease the length of the $\mathrm{S} \cdots \mathrm{S}$ interactions. The short interactions about the $\mathrm{S}$ atoms in phase I thus act as an effective brake to further closing up of the voids and the change in conformation which occurs in the phase transition alleviates the steric hindrance between neighbouring $\mathrm{CH}_{2}-\mathrm{SH}$ groups.

Paradoxically, the data in Table 3 show that the lengths of the $\mathrm{NH} \cdots \mathrm{O}$ hydrogen bonds either stay much the same or actually become longer in passing from phase I to III, while
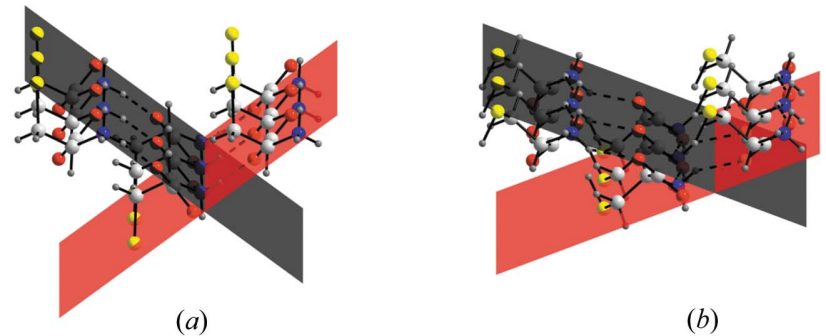

(b)

Figure 9

Staggered $R_{4}^{4}(16)$ ring motifs in $(a)$ L-cysteine-I at $1.8 \mathrm{GPa}$ and $(b) \mathrm{L}$ cysteine-III at $2.6 \mathrm{GPa}$. Red and black planes represent the best plane through $\mathrm{N} 1 \cdots \mathrm{O} 1$ atoms in adjacent $R_{4}^{4}(16)$ ring motifs. Note the reduction in angle between the planes from $72.8(3)^{\circ}$ in $(a)$, to $41.6(3)^{\circ}$ in $(b)$. 
the angles subtended at $\mathrm{H}$ in the $\mathrm{NH} \cdots \mathrm{O}$ hydrogen bonds are somewhat smaller than in the corresponding interactions at ambient pressure. This departure from ideal hydrogenbonding geometry presumably reflects the compromise that needs to be reached between more effective packing and the geometry of specific intermolecular contacts as pressure is increased.

The resistance to compression of the head-to-tail $\mathrm{N} 1 \mathrm{H} 7 \cdots \mathrm{O} 2$ hydrogen bonds has been referred to above; this interaction is formed along $\mathbf{c}$ in both phases I and III, and the $c$ axes are the same length in both phases. The $a$ axis in Lcysteine-III at $2.6 \mathrm{GPa}$ is longer by $c a 0.5 \AA$ than that in Lcysteine-I at $1.8 \mathrm{GPa}$. This is related to the smaller amplitude in phase III of the sinusoidal conformation of the layers formed by the $R_{4}^{4}(16)$ rings. This can be quantified by comparing the angle between planes formed by $\mathrm{N} 1$ and $\mathrm{O} 1$ atoms in the $R_{4}^{4}(16)$ rings, which decreases from 72.8 (3) to $41.6(3)^{\circ}$ in $\mathrm{L}$-cysteine-I at $1.8 \mathrm{GPa}$ and $\mathrm{L}$-cysteine-III at $2.6 \mathrm{GPa}$, respectively (Fig. 9).

The cell-dimension that exhibits the largest change during the phase transition is $b$, which reduces from 12.000 (3) $\AA$ at $1.8 \mathrm{GPa}$ to 10.4883 (19) $\AA$ at $2.6 \mathrm{GPa}$. The reduction is related to the flattening of the layers described above, but also to the conformational change in the cysteine molecules, which makes the $-\mathrm{CH}_{2}-\mathrm{SH}$ groups rotate, allowing the layers to move closer together.

\subsection{L-Cysteine-IV}

L-Cysteine-III is stable to at least $4.2 \mathrm{GPa}$. Similar cell dimensions were observed for phase III at similar pressures during the compression and decompression phases of experiments. This has been a consistent feature of compression studies of other amino acids, which tend to be quite elastic. However, on decreasing the pressure to $1.8 \mathrm{GPa}$ L-cysteine-III converts not to L-cysteine-I, but instead to another, previously unobserved, phase of cysteine, L-cysteine-IV. Like the I-to-III transition, this phase change occurs from one single-crystal form to another. In most experiments the transition resulted in such a marked increase in mosaic spread that although unitcell dimensions could be determined, intensity data were of very low quality. Many attempts were made to obtain a better sample suitable for structure determination, with the best data obtained in a study using pentane-isopentane; the pressure on a crystal of L-cysteine-I was increased rapidly in $1.5 \mathrm{GPa}$ steps in quick succession from $0.3 \mathrm{GPa}$, to a final pressure of 4.2 $\mathrm{GPa}$ (formation of phase III being confirmed by singlecrystal diffraction) and then reduced back down to $1.7 \mathrm{GPa}$.

L-Cysteine-IV is an intermediate in the phase transition between L-cysteine-III and L-cysteine-I. The structure of Lcysteine-IV contains elements of both phases I and III, with the two molecules that comprise the asymmetric unit in the $g^{+}$ and $g^{-}$conformations found in phases I and III, respectively. It was noted above that the geometric parameters which characterize the hydrogen bonds in L-cysteine-III show some departure from ideal values. Molecule 1 in L-cysteine-IV is in the same conformation as the molecules in L-cysteine-III, and the geometries of its intermolecular interactions are also similar to those observed in phase III. That this phase should be unstable as the pressure is reduced is therefore understandable and on further reduction of pressure it transforms completely to L-cysteine-I.

While the formation of intermediate phases is uncommon in molecular systems, it has been observed in some 'inorganic' systems. $\mathrm{CsCuCl}_{3}$, for example, exhibits related dynamically and statically disordered phases (Christy et al., 1994). The lowpressure, low-temperature phases of anorthite and clinopyroxene are formed by zone-boundary transitions from the highpressure or high-temperature structures, and have structures that are made up of the alternation of portions of the highpressure and high-temperature structures (Christy \& Angel, 1996). Additionally, lithium transforms between two cubic phases via an intermediate rhombohedral phase, while in $\mathrm{PbTe}$ the transformation from a $\mathrm{NaCl}$ to a $\mathrm{CsCl}$ structure occurs via an intermediate orthorhombic phase (Rousse et al., 2005).

\section{Conclusions}

We have described the effect of pressure on the crystal structure of L-cysteine-I to $1.8 \mathrm{GPa}$. The structure can be considered to consist of layers that lie within the ac plane constructed from $R_{4}^{4}(16)$ ring motifs that, in projection, have a sinusoidal appearance. These layers are then linked along the $b$ direction by $R_{3}^{3}(9)$ ring motifs. The main response of $\mathrm{L}-$ cysteine-I to pressure is ascribed to the closing up of voids within these ring motifs. At $1.8 \mathrm{GPa}$ the $\mathrm{N} \cdots \mathrm{O}$ distances fall into the range $2.7-2.9 \AA$, which is quite normal for such interactions even at ambient pressure. However, the $\mathrm{S} \cdots \mathrm{S}$ distances are very short $[3.450$ (4) $\AA$ ] and beyond $1.8 \mathrm{GPa}$ a phase transition occurs to L-cysteine-III. As was described in $\S 1$, this behaviour is consistent with the behaviour of other amino acids under pressure.

The phase change from L-cysteine-I to L-cysteine-III is accomplished by a change in the NCCS torsion angle and small positional displacements with no major changes in the orientations of the molecules. The transition from one singlecrystal to another is therefore not surprising. Like L-cysteine-I, the structure of L-cysteine-III comprises $R_{4}^{4}(16)$ and $R_{3}^{2}(9)$ ring motifs; the torsion twist about NCCS alleviates the close S...S contact formed at $1.8 \mathrm{GPa}$, and allows voids within these ring motifs to be compressed further.

L-Cysteine-III was found to be stable to at least $4.2 \mathrm{GPa}$. On decompression to $1.7 \mathrm{GPa}$, another single-crystal to singlecrystal phase transition was observed to L-cysteine-IV, a transition that is not observed on increasing pressure. The structure consists of two crystallographically independent cysteine molecules in the same conformations as those found in L-cysteine-I and L-cysteine-III. The structure separates into zones which are alternately phase-I-like and phase-III-like. LCysteine-IV can therefore be thought of as an unusual example of an intermediate phase. On further decompression to ambient pressure, diffraction data collected on a small crystallite from the now polycrystalline sample confirmed a return to the ambient pressure, L-cysteine-I phase. 
We thank the EPSRC, and The University of Edinburgh for funding and the CCLRC for provision of neutron and synchrotron beam-time. We also thank Professor Ross Angel (Virginia Tech.) for helpful discussions and Dr John Warren (Daresbury Laboratory) for his help with the synchrotron data collection.

\section{References}

Allan, D. R. \& Clark, S. J. (1999). Phys. Rev. Lett. 82, 3464-3467.

Allan, D. R., Clark, S. J., Ibberson, R. M., Parsons, S., Pulham, C. R. \& Sawyer, L. (1999). Chem. Commun. pp. 751-752.

Allan, D. R., Parsons, S. \& Teat, S. J. (2001). J. Synchrotron Rad. 8, 10 17.

Allen, F. H. (2002). Acta Cryst. B58, 380-388.

Allen, F. H. \& Motherwell, W. D. S. (2002). Acta Cryst. B58, 407-422.

Altomare, A., Cascarano, G., Giacovazzo, G., Guagliardi, A., Burla, M. C., Polidori, G. \& Camalli, M. (1994). J. Appl. Cryst. 27, 435-435.

Betteridge, P. W., Carruthers, J. R., Cooper, R. I., Prout, K. \& Watkin, D. J. (2003). J. Appl. Cryst. 36, 1487.

Boldyreva, E. V. (2003). J. Mol. Struct. 647, 159-179.

Boldyreva, E. V. (2004a). J. Mol. Struct. 700, 151-155.

Boldyreva, E. V. (2004b). NATO Science Series, II: Mathematics, Physics \& Chemistry, edited by A. Katrusiak \& P. F. McMillan, Vol. 140, pp. 495-512. Dordrecht: Kluwer Academic Publishers.

Bondi, A. (1964). J. Phys. Chem. 68, 441-451.

Bruker (2002). SMART. Bruker AXS Inc., Madison, Wisconsin, USA.

Bruker (2004). SAINT, Version V7.12A. Bruker AXS Inc., Madison, Wisconsin, USA.

Bruno, I. J., Cole, J. C., Edgington, P. R., Kessler, M., Macrae, C. F., McCabe, P., Pearson, J. \& Taylor, R. (2002). Acta Cryst. B58, 389397.

Christy, A. G. \& Angel, R. J. (1996). Phys. Chem. Miner. 22, 129-134. Christy, A. G., Angel, R. J., Haines, J. \& Clark, S. M. (1994). J. Phys. Condens. Matter, 6, 3125-3136.

Clark, S. J., Ackland, G. J. \& Crain, J. (1998). Europhys. Lett. 44, 578584.

Cooper, R. I., Gould, R. O., Parsons, S. \& Watkin, D. J. (2002). J. Appl. Cryst. 35, 168-174.

Crystal Impact (2004). DIAMOND, Version 3.0. Crystal Impact GbR, Postfach 1251, 53002 Bonn, Germany; http://www.crystalimpact.com/diamond.

Dawson, A., Allan, D. R., Belmonte, S. A., Clark, S. J., David,W. I. F., McGregor, P. A., Parsons, S., Pulham, C. R. \& Sawyer, L. (2005). Cryst. Growth Des. 5, 1415-1427.

Dawson, A., Allan, D. R., Clark, S. J., Parsons, S. \& Ruf, M. (2004). J. Appl. Cryst. 37, 410-416.

Derewenda, Z. S., Lee, L. \& Derewenda, U. (1995). J. Mol. Biol. 252, 248-262.

Desiraju, G. R. \& Steiner, T. (1999). The Weak Hydrogen Bond in Structural Chemistry and Biology. IUCr Monographs on Crystallography, No. 9. Oxford University Press.

Fabbiani, F. P. A., Allan, D. R., David, W. I. F., Moggach, S. A., Parsons, S. \& Pulham, C. R. (2004). CrystEngComm, 6, 504-511.

Fabbiani, F. P. A., Allan, D. R., Dawson, A., David, W. I. F., McGregor, P. A., Oswald, I. D. H., Parsons, S. \& Pulham, C. R. (2003). Chem. Commun. pp. 3004-3005.

Fabbiani, F. P. A., Allan, D. R., Marshall, W. G., Parsons, S., Pulham, C. R. \& Smith, R. I. (2005). J. Cryst. Growth 275, 185-192.

Fabbiani, F. P. A., Allan, D. R., Parsons, S. \& Pulham, C. R. (2005). CrystEngComm, 7, 179-186.

Farrugia, L. J. (1999). J. Appl. Cryst. 32, 837-838.
Görbitz, C. H. (1990). Acta Chem. Scand. 44, 584-590.

Görbitz, C. H. \& Dalhus, B. (1996). Acta Cryst. C52, 17561759.

Gutmann, M. J. (2005). SXD2001. ISIS, Facility, RutherfordAppleton Laboratory, Oxfordshire, England.

Harding, M. M. \& Long, H. A. (1968). Acta Cryst. B24, 10961102.

Hemley, R. J. \& Dera, P. (2000). Rev. Mineral. Geochem. 41, 335419.

Hummer, G., Garde, S., Garcia, A. E., Paulaitis, M. E. \& Pratt, L. R. (1998). Proc. Nat. Acad. Sci. USA, 95, 1552-1555.

Hušák, M. \& Kratochvila, B. (2003). J. Appl. Cryst. 36, 1104.

Katrusiak, A. (2004). NATO Science Series, II: Mathematics, Physics and Chemistry, edited by A. Katrusiak \& P. F. McMillan, Vol. 140, pp. 513-520. Dordrecht: Kluwer Academic Publishers.

Keen, D. A., Wilson, C. C. \& Gutmann, M. J. (2006). In preparation.

Kerr, K. A. \& Ashmore, J. P. (1973). Acta Cryst. B29, 2124-2127.

Kerr, K. A., Ashmore, J. P. \& Koetzle, T. F. (1975). Acta Cryst. B31, 2022-2026.

Lozano-Casal, P., Allan, D. R. \& Parsons, S. (2005). Acta Cryst. B61, 717-723.

Luger, P. \& Weber, M. (1999). Acta Cryst. C55, 1882-1885.

McGregor, P. A., Allan, D. R., Parsons, S. \& Pulham, C. R. (2005). Acta Cryst. B61, 449-454.

Merrill, L. \& Bassett, W. A. (1974). Rev. Sci. Instrum. 45, 290294.

Moggach, S. A., Allan, D. R., Lozano-Casal, P. \& Parsons, S. (2005). J. Synchrotron Rad. 12, 590-597.

Moggach, S. A., Allan, D. R., Morrison, C. A., Parsons, S. \& Sawyer, L. (2005). Acta Cryst. B61, 58-68.

Moggach, S. A., Allan, D. R., Parsons, S., Sawyer, L. \& Warren, J. E. (2005). J. Synchrotron Rad. 12, 598-607.

Moggach, S. A., Clark, S. J. \& Parsons, S. (2005). Acta Cryst. E61, o2739-o2742.

Monkhorst, H. J. \& Pack, J. D. (1976). Phys. Rev. B, 13, 51885192.

Murli, C., Sharma, S. M., Karmakar, S. \& Sikka, S. K. (2003). Physica $B$, 339, 23-30.

Oswald, I. D. H., Allan, D. R., Day, G. M., Motherwell, W. S. D. \& Parsons, S. (2005). Cryst. Growth Des. 5, 1055-1071.

Parsons, S. (2004). SHADE. The University of Edinburgh, Scotland.

Perdew, J. P. \& Wang, Y. (1992). Phys. Rev. B, 46, 12947-12954.

Piermarini, G. J., Block, S., Barnett, J. D. \& Forman, R. A. (1975). J. Appl. Phys. 46, 2774-2780.

Prince, E. (1982). Mathematical Techniques in Crystallography and Materials Science. New York: Springer-Verlag.

Rousse, G., Klotz, S., Saitta, A. M., Rodriguez-Carvajal, J., McMahon, M. I., Couzinet, B. \& Mezouar, M. (2005). Phys. Rev. B, 71, 2241161-2241166.

Segall, M. D., Lindan, P. J. D., Probert, M. J., Pickard, C. J., Hasnip, P. J., Clark, S. J. \& Payne, M. C. (2002). J. Phys. Condens. Matter, 14, 2717-2744.

Sheldrick, G. M. (2001). SHELXL97. University of Göttingen, Germany.

Sheldrick, G. M. (2004a). SADABS. University of Göttingen, Germany.

Sheldrick, G. M. (2004b). TWINABS. University of Göttingen, Germany.

Sheldrick, G. M. (1997). XP. University of Göttingen, Germany.

Spek, A. L. (2003). J. Appl. Cryst. 36, 7-13.

Vanderbilt, D. (1990). Phys. Rev. B, 41, 7892-7895.

Watkin, D. J. (1994). Acta Cryst. A50, 411-437.

Watkin, D. J., Prout, C. K. \& Pearce, L. J. (1996). CAMERON. Chemical Crystallography Laboratory, Oxford, England. 